\title{
Folksongs of the Turkic World
}

\author{
János Sipos \\ Institute for Musicology of the Hungarian Academy of Sciences, Budapest, Hungary
}

\begin{abstract}
The long-term goal of my research has been to systematize and compare by musical criteria the folk songs of Turkic groups and ethnicities living around them. Here I rarely touch on instrumental folk music, the repertoire of professional or semi-professional performers, the most recent strata, seldom or just occasionally discuss art music and the cultural, social and anthropological implications of music are only sporadically considered, too. There are close connections between the languages of Turkic groups but their musical stocks are fundamentally different. Actually, that is not surprising, because these people are, at least in part, Turkified, and through their substrata (that is people absorbed by them) they are in genetic and cultural relations with several non-Turkic peoples. My research therefore has repercussions; apart from the Turkic-speaking peoples tied by culture, language and history, upon their neighbors and partly absorbed other peoples, creating the foundation for an even broader future comparative ethnomusicological research of Eurasian groups. This paper is aimed to provide a very short summary about the findings of my field researches into the folk music of different Turkic-speaking people between 1987 and 2015. I introduce the sources, the collecting work and the methods of processing and analyzing the songs. I also give an analytical introduction to the folksong of Anatolian Turks, Azeris, Turkmens, Uzbeks (and Tajiks), Karachay-Balkars, Kazakhs, Kyrgyzs, a Sufi Turkish community in Thrace and the area of the Volga-Kama-Belaya region. Finally comes a conclusion, a musical map and a list of tasks waiting for us.
\end{abstract}

Keywords: ethnomusicology, comparative folk music research, Anatolia, Turkic people, Hungarians

\section{Introduction}

Hungarian prehistory displays a peculiar duality of language and music: the language belongs to the Finno-Ugric family, while several pre-Conquest strata of the folk music are connected to Turkic groups. Intrigued by this phenomenon, Hungarian folk music researchers launched thorough comparative examinations quite early. ${ }^{1}$ In keeping with the noblest traditions of Hungarian folk music research, investigations authenticated by fieldwork have been going on to this day, parallel with the theoretical research. ${ }^{2}$

\footnotetext{
János Sipos is a senior research fellow of the Institute for Musicology of the Hungarian Academy of Sciences, Member of the Hungarian Academy of Arts, Hungarian Representative of the International Council for Traditional Music and lecturer of the Franz Liszt Music Academy.

1 To mention but the most important scholars: Zoltán Kodály (1937-1976) demonstrated Cheremis and Chuvash analogies in the first place; Béla Bartók $(1937,1976)$ drew still valid conclusions about the folk music of Anatolia from a relatively small material; Lajos Vargyas (2005) carried out the comprehensive historical investigation of the folk music of the Volga-Kama region; Bence Szabolcsi $(1935,1947)$ demonstrated even broader international musical connections after surveying an enormous material; Katalin Paksa (1982) studied the eastern relations of our narrow-range tetra- and pentatonic tunes; László Dobszay (1983, 1984) and László Dobszay and Janka Szendrei (1992) — applying a novel approach to the Hungarian folk music material—reviewed the international material in regard to the lament and psalmodic styles, among other things.

2 The most important among them for my present dissertation are Béla Bartók's Anatolian collecting in 1936, László Vikár's and Gábor Bereczki's areal field research in the territory designated by the Volga, Kama and Belaya in 1957-1978 (Vikár, 1993; Vikár-Bereczki, 1971, 1979, 1989, 1999) and my field research activity among Turkic ethnicities since 1987.
} 
At the beginning, the main goal of this research series was to explore the eastern relations of the Hungarian folk music, which gradually broadened into the areal folk music research of the multi-ethnic Volga-Kama-Belaya region. I further expanded it into the comparative investigation of diverse Turkic-tongued groups living over the vast Eurasian territory.

It justifies research into Turkic folk music that these ethnic groups have long been playing salient roles in Asia, and without the exploration of their folk music the musical world of Eurasia cannot be comprehended. What makes this research even more interesting is the fascinating diversity of this music as well as the fact that the connections between the music of these Turkic groups fundamentally differ from their linguistic relations.

In the course of this enormous work a part of the musical map of this vast area stretching from China to Eastern Europe has been plotted (see Figure 1). It is also a fact that no similarly extensive, analytic, comparative folk music research based on field work has been carried out earlier in Asian territories.

\section{Summary of the Research Task}

The long-term goal of my research is to systematize and compare by musical criteria the folk songs of Turkic groups and ethnicities living around them. There are close connections between the languages of Turkic groups but their musical stocks are fundamentally different. Actually, that is not surprising, because these people are, at least in part, Turkified, and through their substrata (that is people absorbed by them) they are in genetic and cultural relations with several non-Turkic peoples. My research therefore has repercussions; apart from the Turkic-speaking peoples tied by culture, language and history, upon their neighbours and partly absorbed other peoples, creating the foundation for an even broader future comparative ethnomusicological research of Eurasian groups.

This paper is aimed to provide a short summary about the findings of my field researches into the folk music of different Turkic-speaking people between 1987 and 2015.

\section{Sources, Collecting Work}

There were no systematized archives for the investigation of Azeri, Karachay-Balkar, Kyrgyz, Aday and Mongolian Kazakh, Turkmen and Sufi popular Islamic music, while the Anatolian and Kazakh collections were hardly accessible. Besides, the material of the latter was poorly annotated, basic genres were missing, such as laments, lullabies, folk religious tunes etc., so I had to carry out extensive field work among several Turkic ethnic groups.

In the past 28 years I spent a total of some 10 years in areas populated by Turkic groups and collected and notated some ten thousand tunes. I worked mostly in small villages and finished collecting among an ethnic group when the newly recorded tunes were already variants of former ones. The created Turkic archive belongs to the major systematized and elaborated collections of Azeri, Kyrgyz, Karachay and Turkmen folk music anywhere in the world. Concerning the degree of notation and analysis, the Anatolian and Kazakh sections are also important. This large amount of tunes allowed us to draw unique and reliable conclusions, and the whole endeavor acquired the value of basic research.

The main groups of tunes I have collected since 1987 are the following: Anatolian (mainly Turkish) people, Azeris, Caucasian and Turkish Karachay-Balkars, western and Mongolian Kazakhs, Kyrgyzs, Turkmens, Sufi Islamic communities and North American Indians. My investigations covered other non-Turkic peoples and religious communities of the area as well. 
The majority of collected tunes are videotaped, a considerable part of the collection has been digitalized; cataloguing and uploading them online are in process. I notated the Anatolian, Azeri, Karachay, Kazakh, Kyrgyz and Turkmen tunes and presented large representative selections together with audio-recordings and video-recordings in my books.

In addition to the works of Hungarian researchers in the Volga-Kama area and their followers ${ }^{3}$ some articles and books have appeared about the folk music of some Turkic groups I studied thoroughly (e.g. Anatolian and Kazakh Turks). In most cases, however, there are only tune selections (Azeri, Karachay, Kyrgyz) or not even that (Turkmen). I have studied the local and foreign folk music researchers' works the great majority of which refrain from classification, let alone comparative examination.

\section{Methods of Processing}

In my work I have applied the methods of comparative folk music research with great Hungarian traditions, of which László Dobszay wrote in an article entitled "The Golden Age and Decline of Comparative Folk Music Research" (2010). However, similarly to him the cultivation of comparative folk music research I also deem vitally important. I resorted to the methods of ethnomusicology adapted to the currently predominant cultural-social anthropological trends in smaller communities such as the Sufi Takhtajis and the Alevi/Bektashi communities, as well as for in-depth research among the Aday and Mongolian Kazakh people. During fieldwork I made numberless interviews with musicians which are still to be processed.

I notated the collected tunes and classified them relying on the methods applied by my predecessors (Kodály, 1937-1976; Járdányi-Kerényi, 1961; Vargyas, 2005; Dobszay, 1983) to the arrangement of Turkic folk music tunes. When comparing the material with Hungarian folk music, I primarily used Dobszay-Szendrei's (1992) conception of folk music styles.

Let it suffice to note here that the significantly different musical materials required different criteria of classification. For instance, the Azeri, Turkmen and Uzbek songs have short lines of a few neighboring tones as against broad-ranged four-lined pentatonic folksongs implying fifth-shifting. A main criterion of systematization is first of all the melody contour because the rest of the musical features (e.g. rhythmic scheme, syllable number, gamut, etc.) are less markedly characteristic of the tunes, and the grouping on their basis can easily be presented in tabular form.

Let us now survey the main musical styles of some Turkic group, trying to find out what characterizes a people and what can be explained with a "stylistic community". Here, I cannot embark on the description of each folk music style but I assess the most important folk music layers to try and define the mutual places of the Turkic folk music repertoires with a glimpse of the music of some non-Turkic neighbors.

\footnotetext{
3 Vikár (1982), Vikár-Bereczki (1971, 1979, 1989, 1999).
} 


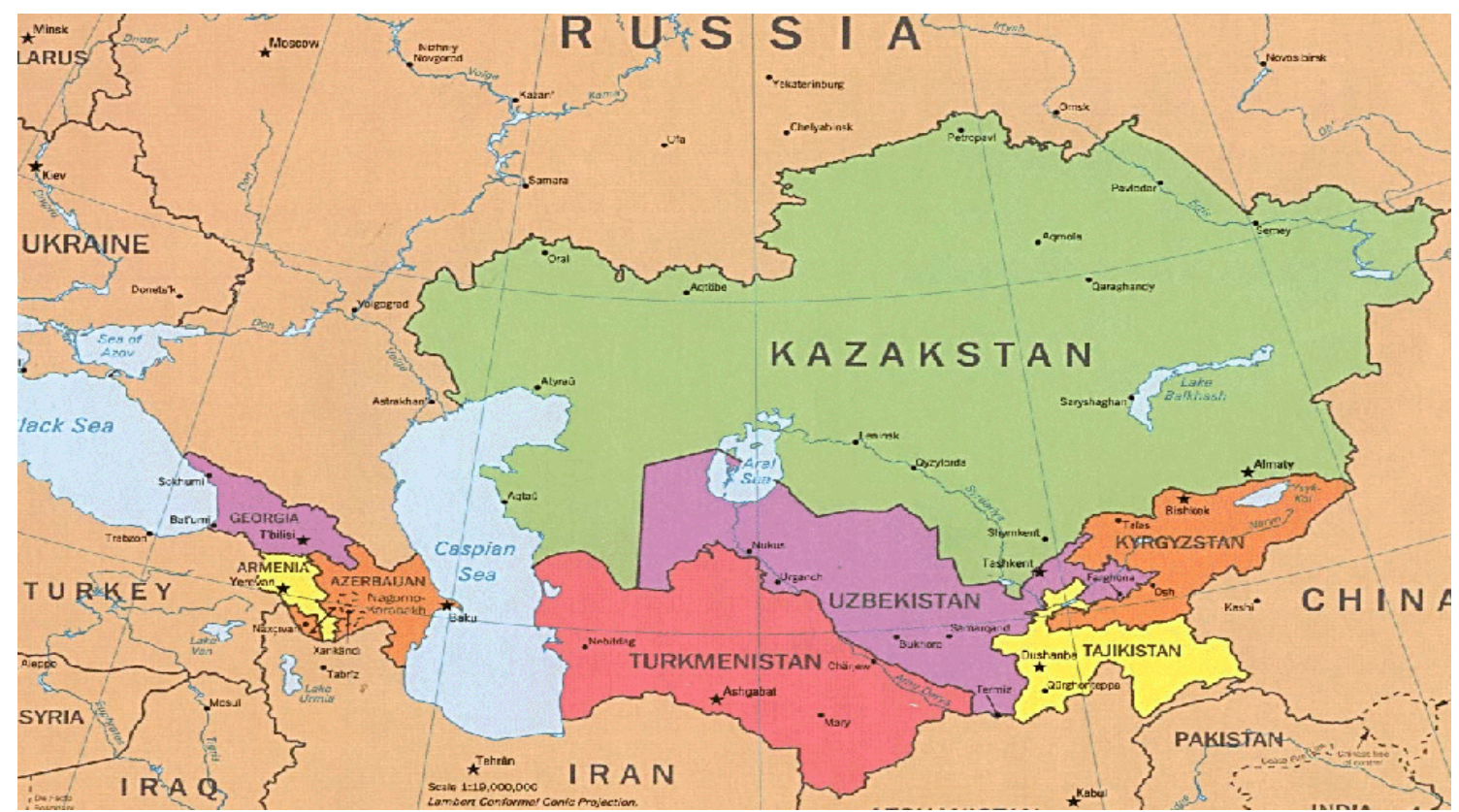

Figure 1. Map of the examined area.

\section{Folksongs of the Anatolian Turks}

The population of nearly 80 million people living in the area is highly complex, and hence their folk music culture is also varied. Apart from diverse groups of Turks and Turkified people, there are Kurds, Laz, Greek, Azeri, and several other ethnic minorities. Many kinds of musical forms crop up ranging from motifs moving on a few notes to descending four-lined structures spanning two octaves. Great differences can be discerned by geographic regions and genres, too: while the folksongs of the Sufi Takhtajis in the Taurus Mountains belong to a single melody group, their religious repertoire includes several fundamentally different forms. In spite of that, a survey of Anatolian folk music is not hopeless. Béla Bartók made an attempt in 1936, and I have surveyed a far larger material myself, too (Sipos, 1994, 1995, 1997).

There are strong musical connections between the Hungarian and Anatolian psalmodic style, the lament style and the tunes of children's games. Hungarian research derives the psalmodic tunes from European origins, the tunes of the small form of the lament style are thought to be a Finno-Ugrian legacy, and the children's game songs of mi-re-do notes rotating around the middle note are known to arise among most diverse ethnic groups independently of each other. My recent investigations tend to suggest that the Anatolian tune types should be conceived as the heritage of the basic Byzantine population tinted with Turkic and other influences. It is an important difference that as compared to several Hungarian musical strata, the Anatolian music is essentially and almost exclusively diatonic.

In addition to diatony, an important feature is the conjunct motion of the melody which develops along neighboring notes and the first half of the tune does not get separated from the second in terms of pitch zone. Despite its variety, these features lend some homogeneity to the great part of the repertoire of the Anatolian region. A disjunct structure, "small fifth-shifting" or "fifth-shifting" only occur sporadically, almost by accident only between the lines within the overall descending tendency. A typical feature is the sequencing of lines or bars in several tunes, and even styles (see Figure 2). There are hardly any tunes of architectonic structure, and if there are some, they are far less developed than their Hungarian counterparts. 


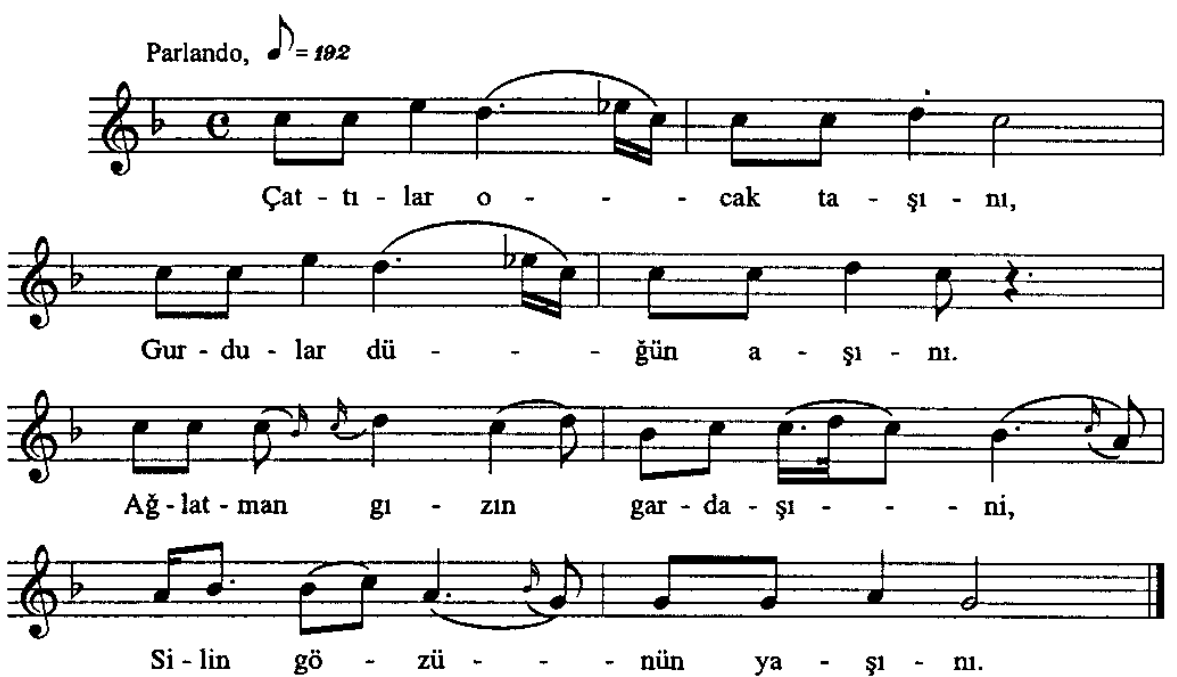

Figure 2. Four-sectioned Anatolian melody with bar sequences (Sipos, 1995: № 223).

Typical of Anatolia is the diversity of asymmetric rhythms whose ancient European (Greek) origin is alluded by to their primary (but not exclusive) presence along the sea shores once populated by the earlier Greek city states and their environs. A few asymmetric rhythmic schemes also occur in the music of the Turkmen tribes of the Taurus Mountains, as well as among Turkmens, Uzbeks, Uyghurs, but are missing from the folksongs of other Turkic groups except for the repertoire of some bards.

The tunes are performed in both free and strict manners, their construction is basically authentic, the last note most often being the lowest pitch as well. The majority of songs are 2-lined or 4-lined or derive from these formulae. Scales with the minor third are predominant, but degrees 2 and 6 are more unstable than the rest, intoned somewhere between the minor and major third and sixth, resp. Degree 2 is practically never absent, while degree 6 is often missing from the scale.

In Anatolian folk music there are numberless Aeolian tri-/tetrachords and even bichord tunes- the bulk of them are one-lined or two-lined in accord with the small compass. There are a considerable number of minor (and major) pentachord tunes, several of which have analogies in Hungarian folk music (see Figure 3).
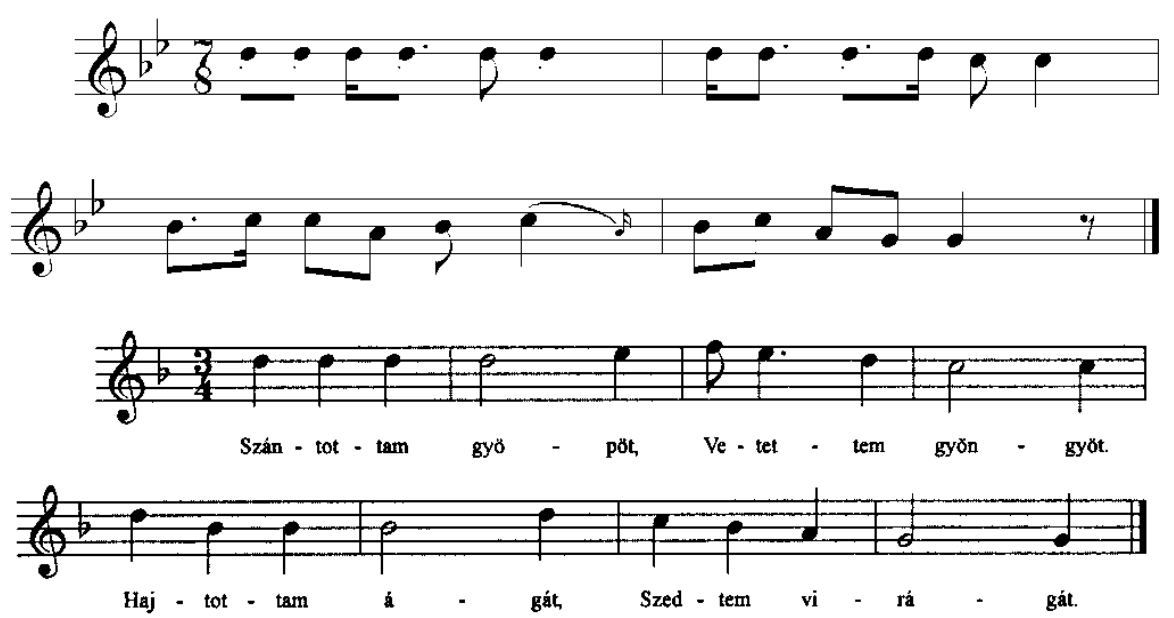

Figure 3. Penthacord Anatolian and Hungarian tunes. 
The compass of the Turkic tunes does not exceed seven notes (1-7), with the exception of some South Turkish uzun hava tunes. Contrary to a generally held view, the scales with augmented seconds are rare and the augmented interval is usually between degrees 2 and 3, sometimes falling just narrow of a real augmentation.

It is impossible to survey the whole repertoire of Anatolia in a few pages, but in my books I introduced the central tunes of the main tune classes from two angles. First, I ranged them in tune groups according to cadence, length and number of lines, and the height of the first line; then I rallied the groups of similar melody motion along one long or two shorter melody lines (or two long and four shorter lines) into respective classes and demonstrated the interrelations of the classes in tables. The tables clearly illustrate which tune classes are preponderant, which are rare or missing. I also demonstrated the present central tunes of the tune classes starting with the twin-bar forms, followed by those retraceable to one long (or two short) lines and finally those that can be traced to two long (or four short) lines. However, the detailed elaboration, comparative analysis and historical exploration of the musical strata of the folk music of this enormous area with a population of some 80 millions are still awaiting the work of contemporary and future generations of folk music researchers.

\section{Folksongs of the Bektashis of Thrace}

I conducted a separate research among a Sufi Turkish group, the Bektashis of Thrace. They are a mystic community of Islam living in the European part of Turkey, migrating here from Bulgaria, and thus knowledge of their music allows an insight into the folksongs of both the Bulgar Turks and a Sufi religious society.

There is much concordance between the Bektashi and the typical Anatolian tunes. Bulky layers are constituted by the mi-re-do-core tunes rotating around their middle note, by diverse forms of the psalmodic style and by the sequentially descending tunes (see Figure 4). Not infrequently, a lengthier tune is built from a single or just two different motifs.

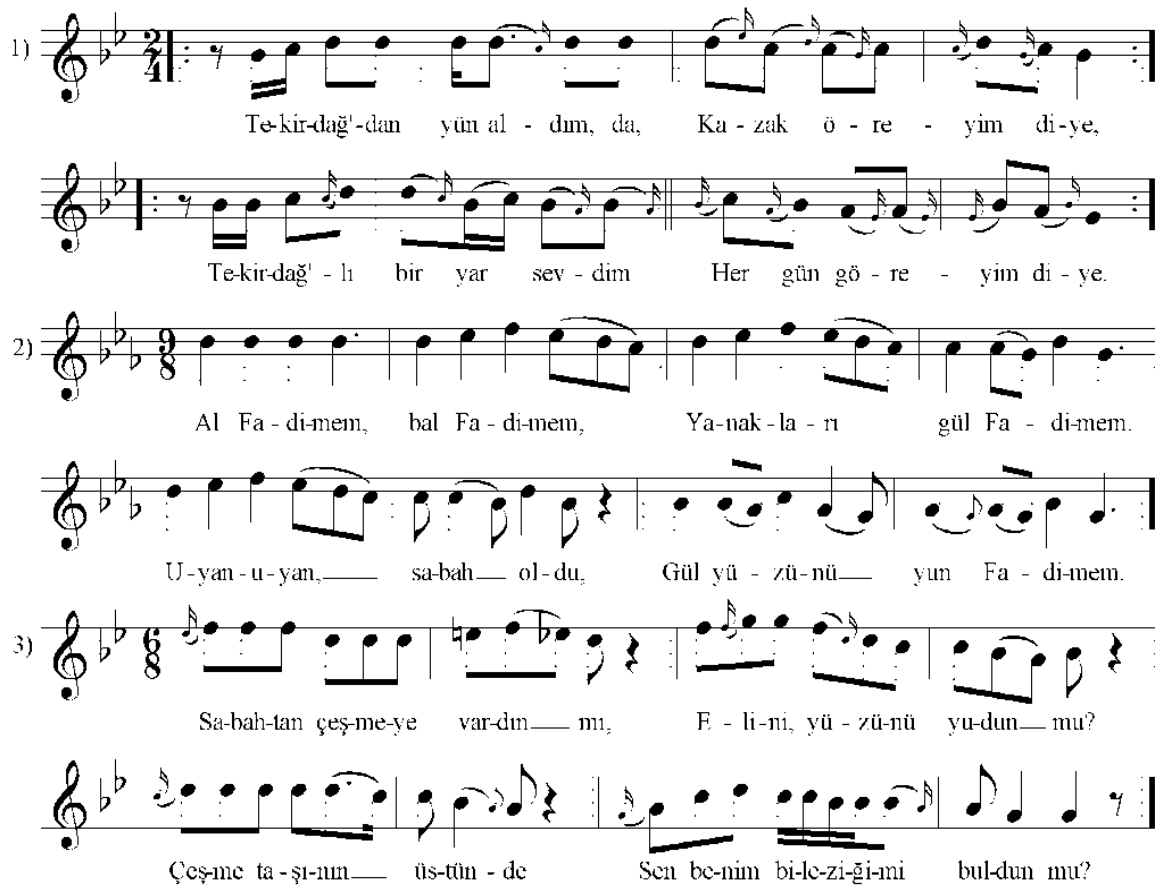

Figure 4. Psalmodic and descending melodies with 5(b3)b3/1 more rarely 4(b3)b3/1 cadences. 
Typical is the conjunct motion and form with descending melodies in lines of convex or descending shape. This applies both to tunes built of variants of a single short hill-shaped la-re-(mi-re)-do-(b)si-la line and to forms of many lines.

In the first line of several Bektashi tunes there is a rise-fall-rise undulation over a narrow tonal range; this is less frequent in Anatolia but can be found as typical in several Turkic groups, e.g. the jir tunes of the Karachays, among Kyrgyz, Aday Kazakh and particularly Mongolian Kazakh people, often with a wider compass, too (see Figure 5).

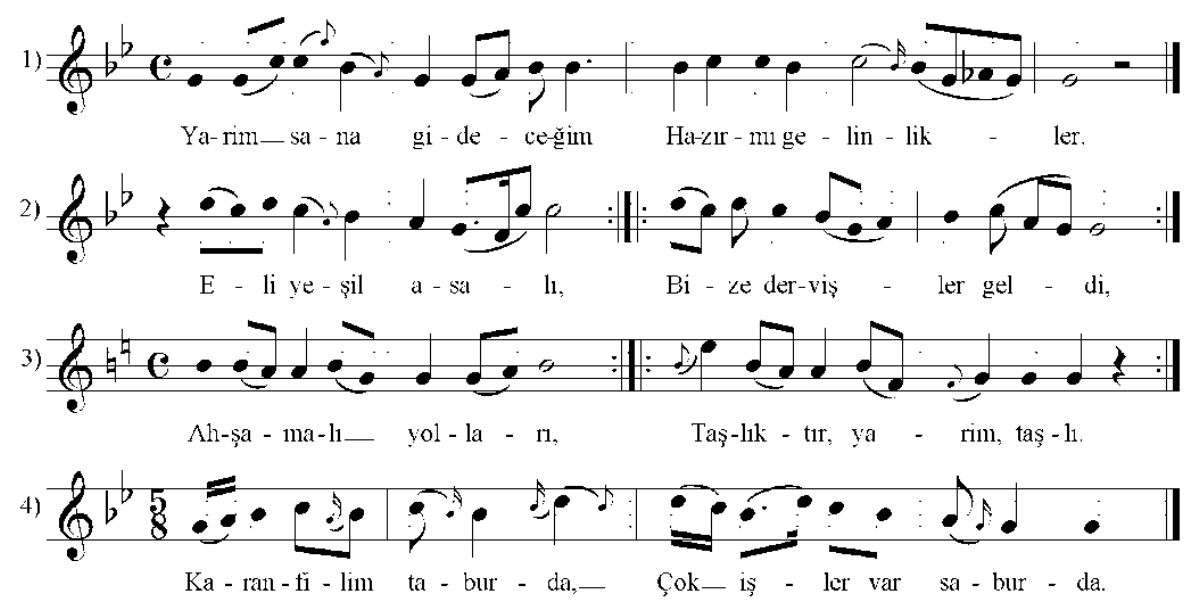

Figure 5. Bektashi melodies with different movements in the first section.

There are disjunct structures as well, but never in pure form. The domed, returning construction is more frequent than in Anatolia; detailed analysis has found these tunes to be specific to the Bektashi community, mainly belonging to their religious repertoire.

Apart from the sol'-mi-re-do-(b)si-la scale, incomplete scales are rare; most interestingly, one is the re-si-la tritonic scale of laments and bride's farewell songs. The small form of the Hungarian and Anatolian lament is not found here.

As is typical of folk religious tunes in general, there is a close connection between Bektashi religious and folk songs. The simplest, single-line small-compass forms dominate folksongs and some religious semah dance tunes, and the wider the compass and the closer we come to four-lined structures, the greater the number of similar religious and folk tunes.

\section{Folksongs of the Azeris}

Progressing eastward from Anatolia, one finds the closest language relatives of the Anatolian Turks, the Azeris. The area of Azerbaijan was Turkified by more or less the same Turkmen tribes as Anatolia, but the substratum upon which they settled was different. That must be the reason why the two folk music stocks are so dissimilar. In Azeri areas the surviving of the music of a complex Caucasian and probably an even more significant Iranian basic layer can be found.

Compared to the highly complex Anatolian folk music, Azeri folk music in the country and beyond, in areas of historical Azerbaijan now in Iran, is rather simple. Melody motion is conjunct; scales with large leaps, melodies rotating around a central core, a starting ascent or tunes retraceable to a single motif or twin bar are very rare. The latter form appears at most in instrumental music. 
The typically single-core or two-core Azeri tunes move in trichords, tetrachords or even bichords of Aeolian, Dorian or Phrygian/Locrian coloration, comprise 7-syllabic, 8-syllabic or less frequently 11-syllabic descending or convex lines rarely arranged into strophes. They are performed in 6/8, 2/4 or other meters based on these, in tempo giusto, rubato or parlando manner (Sipos, 2004, 2005, 2009). Longer lines and/or fixed four-lined structures only sporadically occur here.

It well illustrates the simplicity of the Azeri musical realms that the semi-professional Azeri ashiks only use the simple forms of Azeri folk music, unlike the Turkish or Turkmen bahshis (bards). More complex forms can only be found in instrumental dance music and in the courtly mugam/makam music.

The musical realm of the Azeri tunes is characterized by a plenitude of variations on the basic forms despite the great degree of simplicity.

Let me call attention to three Azeri tune groups. The tunes of one move on the notes of the (sol'-fa)-mi-re-do chords, are performed parlando, their lines end on re or do-thereby resembling the small form of the Hungarian and Anatolian laments. The weight of the analogy is further enhanced by the genre of the tunes being laments in most cases (see Figure 6).

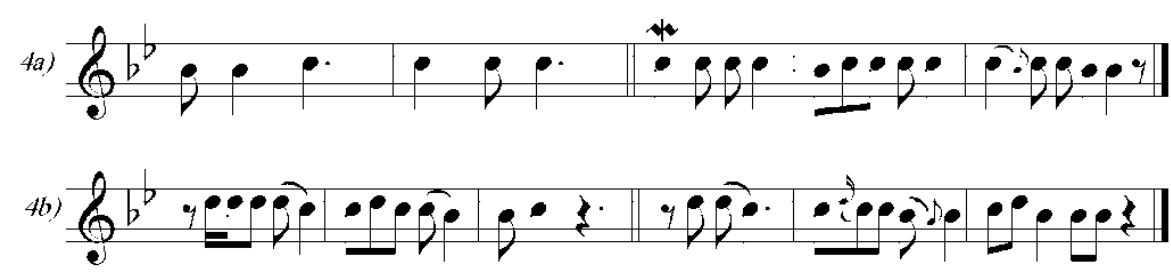

Figure 6. Two Ionian laments with short sections and small compass.

However, this tune type is only a subtype of major character of the Azeri laments which have three modal variants. Another group contains four-lined Aeolian tunes which fit into several Turkic and non-Turkic psalmodic styles. And a few melodies of this group have considerable Turkic and Hungarian backgrounds. However, I only met with such tunes in publications and only found similar tunes among the Avars living in Azeri areas during my field-research. Four-lined constructions are basically rare in Azeri areas, whereas, at least today, they are prevalent in the Hungarian material and characterize at least half the tunes of other Turkic (Anatolian, Karachay, Kyrgyz, Tatar, etc.) groups.

Phrygian/Locrian tune groups built of one or two short narrow-ranged lines acquired greater significance after the analysis of Turkmen (and Tajik) folk music.

The folk music of a few minorities living in Azeri territory is also revealing. I collected music among Avars, Tats, Zakhurs, mountain Jews, Russians and Hemshili Turks. The Tats of southern Iranian origin and the Zakhurs of Caucasian roots largely merged with the Azeris, and the tunes of the basic strata of the Mountain Jews' music who fled here from the eastern Caucasus are also practically indistinguishable from the Azeri tunes.

Different is the case of the Avar, Russian and Hemshili Turkic songs. The Avars constitute the largest and most advanced ethnic group of Daghestan, a part of whom live in today's Azerbaijan. Unlike the rest of the minorities there, they preserve their culture and a great part of their songs are different from the Azeri tunes. Typically enough, about half the Avar tunes I collected more or less fits the psalmodic style. The re-do-la triton of the recorded Russian tunes was really refreshing in the consistently diatonic world. 
The Hemshili Turks migrated here from Georgia; the majority of their tunes are in accord with the basic layers of Azeri and Anatolian folk music, including the small form of the lament style and even a few tune variants of the psalmodic style. They have a few tunes that cannot be found either in Azeri or in Anatolian folk music.

Let us sum up at this point the Hungarian and Turkic relations of Azeri folk music. It immediately strikes the eye that compared to the seemingly homogeneous Azeri tune stock of a few elementary styles, the folk music of several (but not all) Turkic groups and the Hungarians contains many essentially different tune layers. One can find analogies to the majority of Azeri tunes in Anatolia, the most convincing parallels coming from northern Anatolia where the rate of Kurds and Azeris is high. Unlike Hungarian and Anatolian folk music, Azeri tunes are predominated by narrow tonal ranges and the rarity of fixed four-part constructions. Besides, melodies built of trichord or tetrachord motifs rotating around the middle note are only found among instrumental tunes - and infrequently, too. What there is a profusion of in Azeri folk music are the tunes similar to the small form of Hungarian and Anatolian laments. This is perhaps the only folk music form that displays real similarities between Hungarian and Azeri music.

Owing to the absence of pentatony and large tune forms, the diatonic and narrow-compass Azeri tunes have nothing to do with the pentatonic musical layers of Tatars, Bashkirs and Chuvash people living in the region of the Volga, Kama and Belaya. The music of the eastern Chuvash minority and the Christian Tatars includes some narrow-range motivic forms, but they are almost always tritonic or tetratonic tunes containing leaps. In this region, the Mordvin and Votyak folk music contains a few do-re-mi-re-do 3-4-note single-motif hill-shaped lines, but their character is different from the Ionian trichord Azeri tunes.

Since the forbidding mountain range of the Caucasus separates the ethnicities living on either side of it, it is not surprising that the varied folk music of the Karachays and Balkars speaking a Kipchak Turkic tongue hardly have any similar layers to Azeri music.

A bit different is the case of the Mangyshlak Kazakhs on the other side of the Caspian Sea, as they are separated by a sea, and not a mountain range from the Azeris. The central lament stratum of these Aday Kazakhs move on the same Phrygian/Locrian chords — though with a somewhat different logic — as one of the most characteristic tune groups of the Azeris. The Kazakhs of Mangyshlak have far more colourful and numerous musical styles than the Azeris, but their musical styles substantially deviate from the pentatonic musical styles of the Kazakhs in Mongolia more to the east. By contrast, a great part of the Turkmen and Uzbek (as well as Tajik) folksongs — as will be seen—display strong stylistic similarities to the central Azeri folksong types.

\section{Folksongs of the Turkmens}

Let us see now the folk music of Turkmens on the opposite side of the Caspian Sea, across from Azerbaijan. In the ethnogenesis of the Turkmens, a considerable Iranian population took part in addition to Oghuz and Kipchak tribes, which put a deep imprint on their folk music, too.

The melody contour of Turkmen folksongs is just as simple and homogeneous as that of the Azeri tunes, verified by all available publications and my collection of 600 tunes, too. In other aspects, however, they display a rich variety, e.g. in the women's performing style, in peculiar timbres, the use of quarter tones and special micro rhythms, etc. It is quite clear that their repertoire fully satisfies the musical needs of the community. The copious use of micro tones is more an Iranian than a Turkic heritage, also reinforcing the massive Iranian substrata of Turkmen music. 
Turkmen folksongs have narrow compass, move fast, the melody line often descends from the highest to the lowest pitch, and the forms are very simple. Most tunes have two lines, and a considerable portion of the four-lined songs can be directly tied to two-lined versions (see Figure 7).

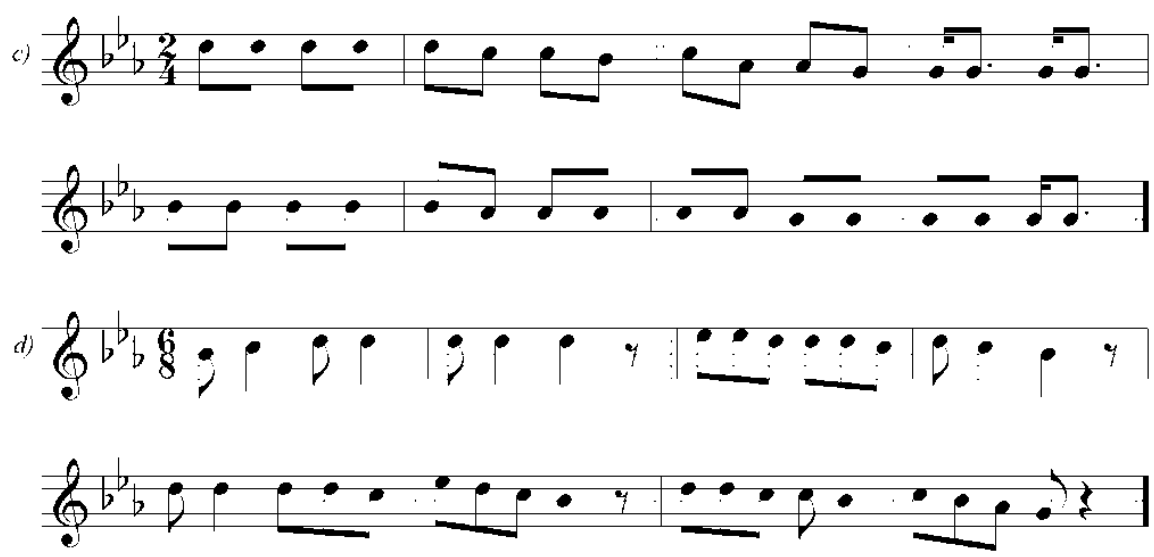

Figure 7. Women songs having four sections c) wedding song (Sipos № 136), d) lullaby (Sipos № 38).

Some tunes recite one or two notes, but the compass of their more melodious pieces does not go beyond a trichord or tetrachord, either. They may have minor or Phrygian character or between the two through the use of micro tones. These tunes are characterized by short lines, simple rhythmic formulae and a descending melody outline. The only popular structuring principle is the descent of motifs in second sequences, which is also frequent in the folk music of Anatolia, but from the equally simple music of Azerbaijan it is almost wholly missing. Compared to Azeri music, Turkmen tunes are often in 5/8 meter. Despite the four-lined text stanzas, one-part or two-part half melodies are most frequent; a melody structure of four different lines is rare.

\section{Comparison of the Azeri and Turkmen Folk Music Repertoires}

The simplest tunes are sung by women in both ethnic groups. By contrast, the (semi)professional singers-Turkmen bahshi, Azeri ashik —and the paid singers of weddings are mostly men.

The folksongs, ritual songs and Islamic religious tunes of both groups are simple, in 2/4 or 6/8 time, often performed rubato (sometimes parlando). Melody lines are 7-syllabic or 8-syllabic, the overall form can usually be derived from one or two lines, the compass rarely goes beyond the fourth, and tunes moving on two neighboring notes are not infrequent. Though accurate intonation is not characteristic of Azeri tunes, in Turkmen folksongs the role of quarter tones is far stronger. In both groups' music the typical rhyme scheme is $a a b a$, and refrains are rare.

Nearly every Azeri tune type has its Turkmen parallel and vice versa. A major difference is that in Turkmen folk music there are considerably fewer tunes moving on Ionian tri-/tetrachords.

The Phrygian (sometimes Locrian) tri-/tetrachord plays an important role in both folk music. Similar simple Phrygian tunes are frequent among the Uzbeks, Tajiks and in Anatolia, too. In Sipos (2004, pp. 106-115) several Azeri-Anatolian parallels are presented.

The repertoire of Azeri ashiks consists mainly of folksongs (Sipos, 2004, pp. 116-118). In the introductory section of their performance Turkmen bahshis also sing simple tunes which, however, often have longer lines than the folksongs and gradually evolve into broader-compass intricately structured compositions. Another 
difference is that the Azeri ashik's instrument is the three-stringed bağlama well-known in Turkey, while the Turkmen ashik prefers the two-stringed dutar. Both ashiks and bahshis may sing solo, may accompany their singing with an instrument and may also have a small ensemble. The instruments of an Azeri ashik's ensemble include the baglama to accompany his singing and play interludes, zurna (sometimes zurnas) and a drum. In a Turkmen bahshi's ensemble there are one or two dutars (plucked lute) and a gijak. Complemented with the blown balaban and a drum, the latter becomes the typical apparatus of Azeri court musical mugam (maqam) performance.

The vocal pieces of Turkmen bahshis are characterized by two basic tune types: (1) narrow-ranged low-register tunes in giusto rhythm similar to folksongs, and (2) more complex tunes in a higher register. The complex forms are sometimes introduced by simple forms that can be derived from or are identical with the second half of 4-lined tunes. With the addition of refrains, the strophic structure can be enormously enlarged.

In the repertoire of Turkmen bahshis many popular Anatolian uzun hava tunes have analogies. The corresponding Turkmen tunes are heavily varied, so much so that sometimes only a tune variant of the performed cycle can be regarded as a parallel to the Anatolian tune. Besides, the cadential notes are far more blurred in the performance of a Turkmen bahshi than in Anatolia.

Both long — often additionally extended - lines of many bahshi tunes descend from high: the first line to degrees 3-4, the second to the tonic note. This scheme is frequent in the Anatolian uzun hava tunes, including the ones called türkmeni around Adana, though the latter often start the descent even higher, from degrees $10-11$.

While further analyses of Turkmen folksong cannot have too much surprise in store, the deeper investigation and analyses of the less studied and constantly changing Turkmen bahshi repertoire should be high on the agenda of folk music research.

\section{Folksongs of the Uzbeks (and Tajiks)}

The neighbors of Turkmens are the Uzbeks, east of whom live the Tajik and Kyrgyz people. The Uzbeks speak a Turkic language, the Tajiks speak an Iranian tongue but the two groups often lived and still live side by side on the same territory and the majority of the population speaks both languages. The music of the two groups is based on similar melodic, modal and rhythmic foundations, many tunes having both Tajik and Uzbek texts.

Uzbek music preserves several forms that can be found among other Turkic musical stocks more to the south, whose melody line comprises both a rotation around the middle note of a trichord and the ascending or convex melody shape where Anatolian (Sipos, 1994, No. 45, 49) and Azeri (Sipos, 2004, No. 318) analogies can also be shown. On account of its improvisatory performance, scale, melody progression and cadences the Uzbek lament reminds one of the bi-cadential Hungarian and Anatolian major hexachord laments, and some laments are even analogous with the Hungarian two-lined lament scheme of minor character.

Several Uzbek laments move on the (mi)-re-do-la tri-tetraton. Such tunes built of motifs are also frequent in the essentially non-pentatonic Kyrgyz (Sipos, 2014), Anatolian (Sipos, 1995, pp. 79-80), and this is less surprising Hungarian music having pentatonic layers (Vargyas, 2005, p. 0148) and in wholly pentatonic Chuvash and Tatar folk music (Vikár, 1993, pp. 107-108).

The rhymes of the Uzbek spring rain magic are recited rhythmically on varied forms of the do-do-do-do re-sol sol motif, but not always on precisely intoned pitches. Motifs and tunes built on the re-do-sol triton can 
be met with in the musical repertoires of several Turkic groups but they are rare as independent motifs in Hungarian folk music. Together with the tune on the re-do-la core these tunes allude to an ancient, pre-pentatony layer of this folk music.

There are two basic melody contours in Uzbek and Tajik folk music: (1) after a jump from the tonic to the highest degree of the scale at the beginning, the melody descends; (2) the melody traces a rising-falling outline. Less frequently undulating motion can also be found. Both melody contours can be found in simpler and more complex tunes.

Simple narrow-compass one-lined or two-lined Phrygian tunes are frequent. As already discussed at several loci, this form together with other simpler forms described in detail in Sipos (2004), presumably represents an Iranian substratum of Turkic folk music. It is also confirmed by its popularity in Uzbek and Tajik folk music.

Four-lined forms are rarer. In the discussed territory a special form of psalmodic tunes can also be spotted but only among the Tajiks and only sporadically. The melody progression of some Tajik melodies is similar to a few psalmodic tunes with the difference that lines 2 and 3 end on degree 2 instead of b3. Such tunes are found in the music of other (e.g. Anatolian Turkic, Kyrgyz, and Karachay) groups but they hardly ever occur in Hungarian folk music. Figure 8 would pass for a Hungarian psalmodic tune, were its main cadence b3. In Tajik folk music a few disjunct structures can also be rarely found.

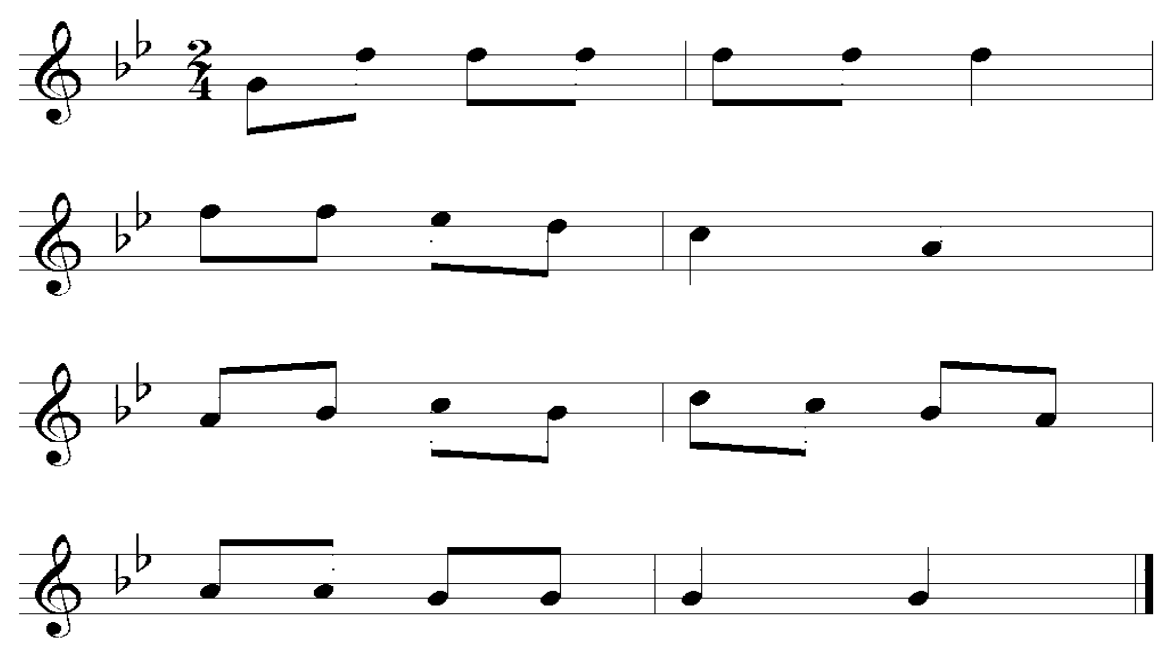

Figure 8. Four-sectioned Tajik song with main cadence on the 2nd degree.

\section{Folksongs of the Karachay-Balkars}

After the Azeri, Turkmen, Uzbek (and Tajik) groups using fairly simple forms, let us move back westward, to the Karachay-Balkars geographically close to the Azeris but separated from them by the impassable Caucasus Mountains. The northern slopes of the Caucasus Mountains are important for Hungarian ethnogenesis and for many Turkic groups: this is where the steppe narrows and where the groups proceeded westward during the great migrations of the Avars, Huns, or, for that matter, landtaking Hungarians.

Though less varied or rich than Anatolian folk music, Karachay music contains several different musical forms many of which have Hungarian connections. In their folk music simpler songs are underrepresented and there are many complex 4-lined forms. They have a tune class of very specific textual subdivision called jir 
which they regard as a typically Karachay form specific to them. However, such tunes can equally - and even more numerously — be found in the music of the Kabards, and since the form of jir tunes is so alien to Turkic music, it is justified to regard them as borrowings from the Kabards.

The typical Karachay tunes trace a descent or a hill-shaped curve in each line, and there is conjunct motion within a line stepping on neighboring notes without large leaps and without going under the cadence note. The overall form is also descending, each consecutive line moving in a bit lower zone. At the same time, it is not infrequent to have an upward leap from the fundamental note or its vicinity at the beginning of the first line, and sometimes there is some up-and-down stepping in the form of rotating around a middle note.

In the contemporary Karachay musical realm tunes built of short motifs are rare. They include the tune bouncing up and down on the fifth, and some rain incantations rotating around the mid-note of the mi-re-do trichord. The latter is a central form of Hungarian, Anatolian and Karachay children's songs and is one of the main types of rain-making incantations. Similarly to Azeris, Turks and Kazakhs, some tunes of the Quran recitation also rotate on the mi-re-do trichord and end on re.

Karachay folk music also contains plagal tunes with falling-rising melody contour. Such are the Hungarian regös tunes whose origins and relations have been moot questions of folk music research since the turn of the 20th century. Many regard them as vestiges of shaman rituals which incorporated Byzantine, Slavic and Caucasian influences still before the Hungarian conquest of the Carpathian Basin. At any rate, this kind of tunes (like the regös tunes in Hungarian music) is alien in Karachay folk music, but their texts-just like those of the Hungarian counterparts-allude to very ancient traditions; the genres of several pertinent songs are rain magic, lullaby or tune of some archaic religion (see Figure 9).

a)
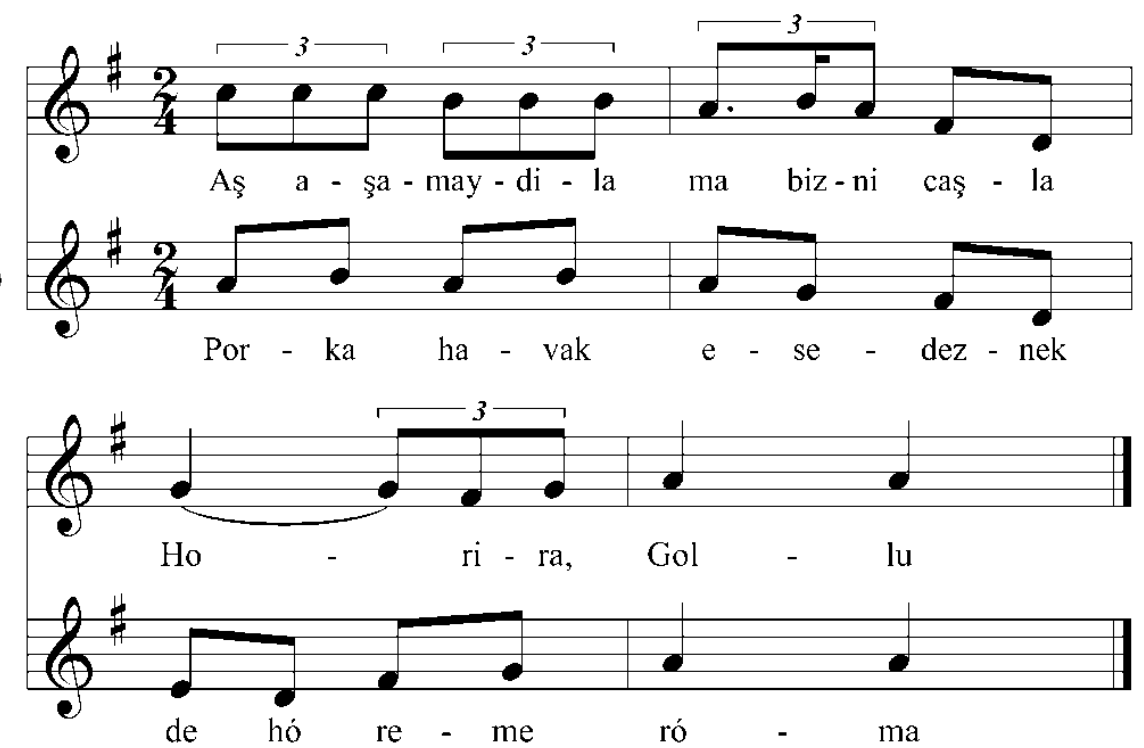

Figure 9. a) "Gollu" melody of the ancient Karachay religion, b) Hungarian "regös" melody.

The opposite of the typical hill-shaped or descending line forms is the concave, valley-shaped line or a line sinking to the fundamental note in mid-line. Sometimes one finds an ascending first line, too. About $10 \%$ of the presented tunes have descending or concave first lines, so these tunes are not exceptional in the Karachay musical realm, even if in the collected material their rate is lower. What is truly rare is an upward jump after a lengthier stay on lower notes, and also rare is a melody progressing on the notes of a broken chord. A 
line-ending leap from degree VII to b3 can sometimes be met with, and a jump down to degree V in some archaic tripodic tunes is also possible. In a few bars of several tunes there are larger skips, which deviate from the general conjunct melody progression of Karachay music.

Many Karachay tunes consist of one or two short lines and their variants. Line variants end on the same note as the preceding line but each subsequent line moves within a narrower compass. Descending and hill-shaped, convex lines are frequent. Nearly every southern Turkic group has such melody patterns among their tunes. Owing to descent and convex line shape, grouping by cadence is satisfactory; I discuss the Karachay tunes of major and minor characters together. It well describes the structural development of Karachay folk music that even its most elementary tunes become arranged into four-line forms. The main cadence is most often (1), (2) — of lament character, or (b3) or rarer (4) or (5), the latter mainly in religious zikr tunes.

With their free performance, improvisatory treatment of the lines and descending melody contour some of the two-core Karachay tunes of major character with (2) main cadence do conjure up the realm of Hungarian, Anatolian and Azeri laments. The type that descends on a major hexachord, cadences on re and do is part of a broader musical style of rubato performance in Karachay (and Kabard) folk music including heroic songs. Similarily to the downward extension of the end of some Hungarian laments, the melody may be enlarged, the line sequences may be enlarged in $\left(l a^{\prime}-\right.$ sol' $\left.^{\prime}\right)-f a-r e-d o \rightarrow(s i)$-sol direction, too.

Undulation is characteristic of the lines of several tripodic tunes with (b3), (4) or (5) main cadences - this melody motion has already been seen in the music of several discussed Turkic groups.

The overwhelming majority of tunes in today's Karachay music have four-lined forms. Below I touch on some of the most important groups.

\section{Four Short or Tripodic Lines With (2) and (b3) Main Cadences}

They descend evenly on minor character scales, from a typically higher starting line, medium-range middle lines and a lower fourth line. This summary description applies to two different subgroups. The lines of one descend with second sequences - these are apparently more recent tunes. The other very popular form has a more symmetrical, more dignified structure, its general description satisfying the criteria of the psalmodic style of Hungarian and many other ethnic folk musics. A part of the Karachay psalmodic tunes are religious (zikr) tunes, but there are several lullabies, which suggests that the form is more archaic and was later incorporated in the religious repertoire. There are tunes of similar melody progression but their main cadence is (2).

\section{Four Short Lines With (4/5) Main Cadences and a Higher Beginning (see Figure 10)}

In accord with the broader compass the melody outline is descending and sometimes exact or partial fourth-shifting and fifth-shifting can emerge, but a descent on second sequences is not exceptional, either. The series of cadences aptly characterize the tune groups: 5(4)x, 4(5)x, 5(5)x, 6(5)4/5, 8(4)x and 7(5)b3. 


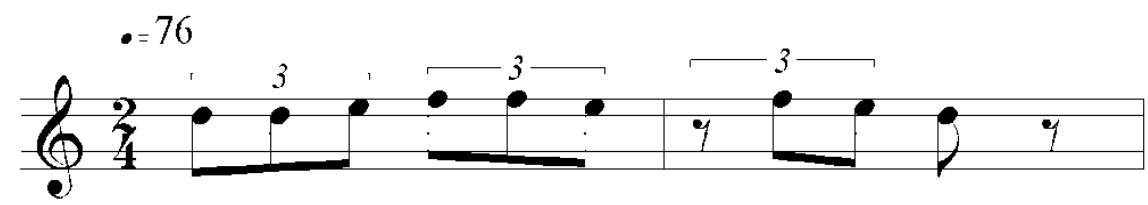

Taw - la - da ay - lạ- nan ki - yik - le

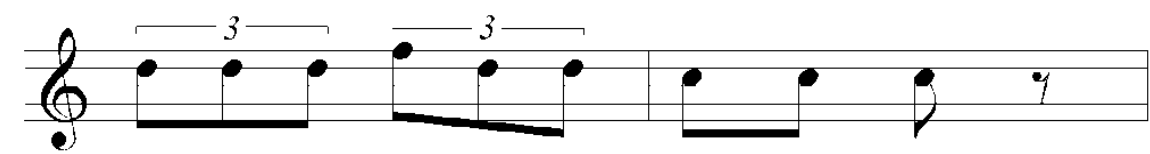

Ki - yik - ni ul - lu - su cu - u - lur

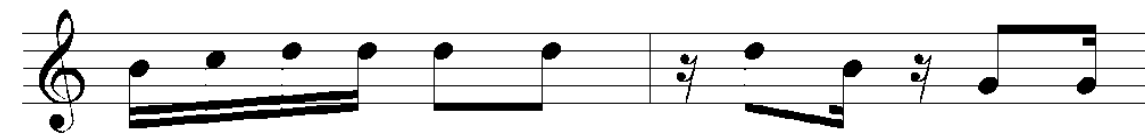

A - man ti - şi - ruw - a $\quad$ sı $-111-s a \eta$ da

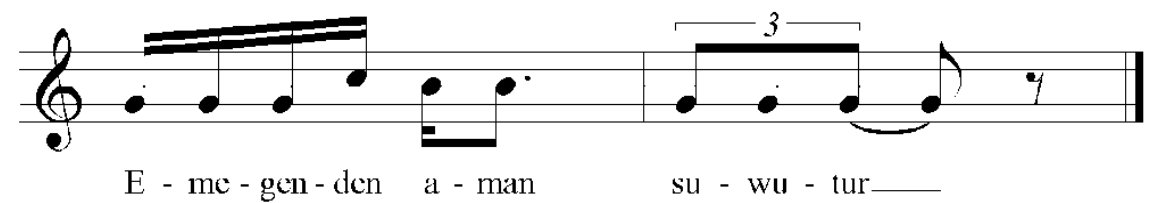

Figure 10. Melody with four short lines and 4 main cadence.

\section{Four Short Lines With 7 or Higher Main Cadences (see Figure 11)}

The main lineament of these tunes is that their first line moving basically on degrees 7-8 may rise as high as the tenth degree and end high, on degrees 7,8 or 9 . The typical cadential series are $5(7 / 8) 5$ and $7 / 8(7 / 8)$.

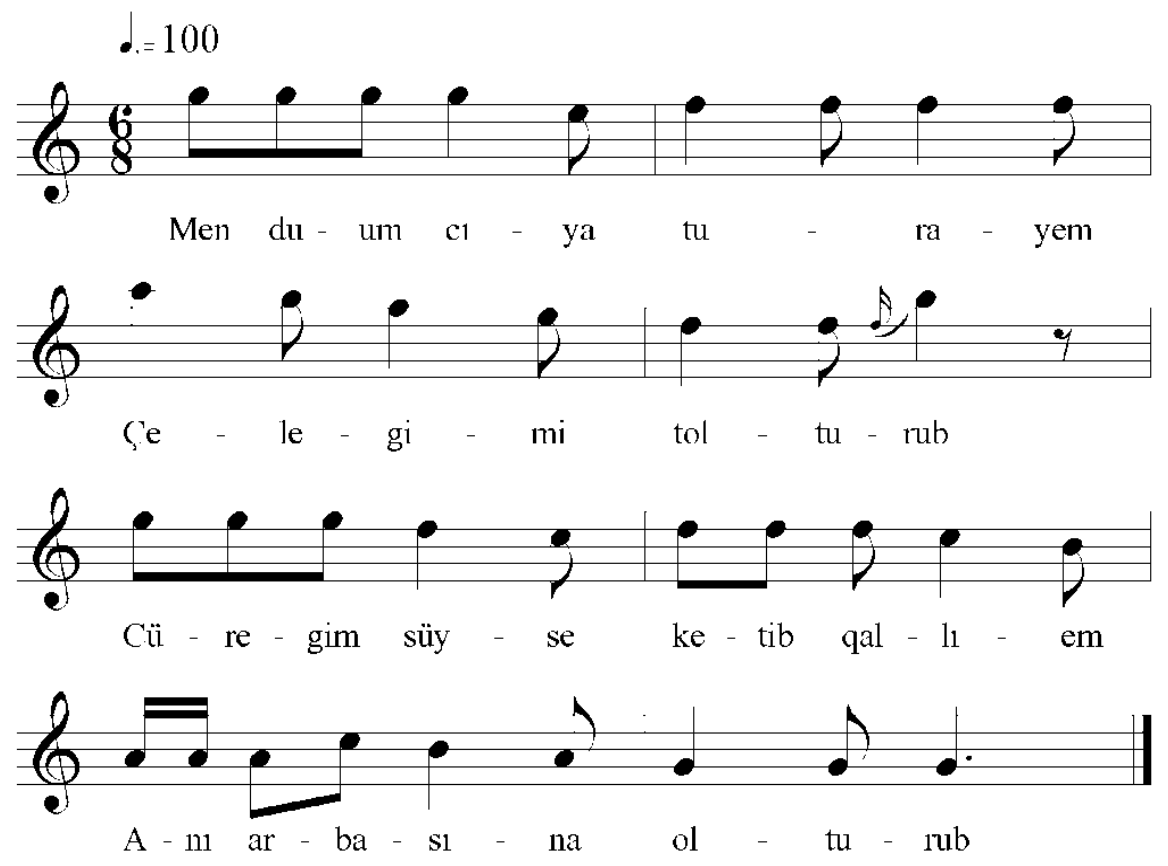

Figure 11. Melody with four short lines and main cadence on the 8th degree. 
There are four-lined pseudo-domed $\left(\mathrm{AB} / \mathrm{A}_{\mathrm{v}} \mathrm{C}\right)$ and domed Karachay tunes of four short lines, too. These, however, do not echo the returning structure of the Hungarian new style because lines one and three are identical or at least similar and their second line is also low. Many signs indicate that these tunes belong to a more archaic style. Some small-domed tunes have their first and fourth lines run low and the interim lines a bit higher; these also deviate from the majority of Karachay tunes.

At last, I mention a few Karachay tunes with four long lines and returning structure, in which the inner lines are a fourth or fifth higher than the outer ones. These appear to be of a more recent style and display strong similarity to some Hungarian new style tunes.

\section{Karachay-Balkar jir Tunes}

At the beginning of my field research I took note of a peculiar tune type whose variants were found later, too, at every collection site. I gave a detailed account of them, so let it suffice here to repeat that most probably the jir style is a borrowing from the neighboring Adyghe people among whom it enjoys extraordinary popularity while no trace of it can be found among other Turkic groups.

In sum, within a broad stylistic similarity, more concrete likenesses can be discovered between Karachay and Hungarian children's songs. A part of the Karachay-Balkar psalmodic, descending and lament tunes probably belong to the same primeval "stylistic species"- to use Bartók's term-as the corresponding Hungarian, Anatolian, even Bulgarian, Slovakian, Romanian and some other ethnic tunes. Aside from characteristic ethnic and areal differences, the overall stylistic similarity, the closeness of individual phenomena, the melody writing, etc. urge for the continuation of research into the common origin or at least the close musical connections of these musical repertoires. A lot of Karachay tunes have convincing or more distant Hungarian analogies and historical sources permit the assumption that there might be genetic relationship between certain layers of Hungarian and Karachay folk music. At any rate, it can be declared that after Anatolian folk music it is Karachay music that displays the closest similarity to the more archaic and non-pentatonic layers of Hungarian folk music.

To be able to draw further conclusions, we should get a deeper insight into the folk music of the neighbours of the Karachays, the Osetians, Kabards and Cherkesses, which contains several similar strata to Karachay-Balkar music. One can find Kabard parallels to several tunes or even groups of the most important and most widespread Karachay-Balkar tune class, jir. The Karachay research has confirmed that the music of an individual ethnic group cannot be studied separately; the comparative examination of the culture of peoples living on wide contiguous areas is indispensable.

\section{Folksongs of the Kazakhs}

In the area of Kazakhstan equal in size to Europe several musical researches have been conducted, but no synthesis has been completed or thorough analytic descriptions written. Beliaev's (1975, pp. 77-78) summary statement is that the Kazakh tune types rest on a common national foundation and are special realizations of the Kazakh national melody character, but Slobin (Beliaev, 1975, p. 123) disagrees. In general it can be stated that in addition to the regional styles, there is a great variety of tunes, a wealth of expressive details and a close connection with live speech in many Kazakh areas.

I have compared the folk music of the southwestern Aday Kazakhs and the Mongolian Kazakhs. It has turned out that despite the near-identity of their tongues, the Aday tunes move in narrow ranges along diatonic 
scales, as against the wide-compass pentatonic folksongs of passionate undulation among the Mongolian Kazakhs, while the latter do not resemble the pentatonic tunes of the Mongols, either. The Aday Kazakhs have more, and more diverse musical styles than the Azeris or Turkmens and their tunes substantially differ from the pentatonic musical styles of the Kazakhs living more to the east.

Let me summarize the conclusions drawn from the comparison of the folk music of Kazakhs in Mangyshlak in southwest Kazakhstan and those living in Bayan-Ölgiy area in Mongolia.

Melody contours. Apart from descending lament tunes, the first lines of Mongolian Kazakh melodies have a convex or concave curve, or a combination of the two tracing a hill-and-vale line. Also frequent are the more restless different up-and-down oscillating tunes, those reciting some neighbouring tones or again others bouncing on a few notes. Though the second half of Mongolian tunes is lower than the first, one only exceptionally finds fourth or fifth correspondences between the lines.

In Mangyshlak the first line of the Aday Kazakh tunes moving on minor-character scales is typically convex; a gentler version of narrower compass can be found in the laments, psalmodic tunes and some narrow-range tunes. The first line of their wider compass two-lined la-pentatonic tunes and of the single noteworthy tune group ending on $d o$ traces a hill. This hill-shaped curve appears to be a characteristic line form that underlies the homogeneity of the Magyshlak tunes. There are few tunes here that have a marked descent, or ascent or hill-and-vale shape. The rest of the "melodious" forms are almost wholly absent. All this widely differentiates this music from the versatile music of the Mongolian Kazakhs.

Let us compare the tunes of the two Kazakh areas on the basis of the melody progression or, more precisely, the contour of the first line.

The descending melody line of the Mongolian Kazakh laments is rare in this region which prefers finely arched lines, while the lines of the Aday Kazakh laments tracing shallow hills fit snugly among the other tunes there. The two lines progressing one under the other of the Aday Kazakh and Anatolian (as well as Hungarian) laments are structurally related with the lines ending on juxtaposed notes, but the tone sets are different. By contrast, the tone set of the Mongolian Kazakh laments is similar to Hungarian and Anatolian laments but their structures are different. These laments can eventually be retraced to the combination of four gradually lower hill-shaped motifs. Progressing from high to low, the motifs are: (1) sol'-la'-sol'-fa-mi, (2) mi-sol'-(fa)-mi-re, (3) sol'/re-mi-re-do, (4) re-mi-re-do-si. These motifs are used by the laments of different ethnic groups as building block in the following way: Kazakhs of Mangyshlak: 1 and 1+2; Mongolian Kazakhs: 3; Anatolian Turks and Hungarians: 2, 3 and 2+3. Anatolian and Hungarian laments are closest to one another, the Mongolian Kazakh laments are similar to them but the realm of the Mangyshlak laments is different.

It applies to both Kazakh areas that the first line traces a well discernible hill or vale, or a clearly descending or ascending melody section. The more "melodious" lines of Mongolian Kazakhs contain two of the sections (of hill, valley, ascent, descent) at most. Repeated or varied motivic bar structures can often be discovered in these tunes: the rising-falling-rising wavy lines are often built of $a b a$ bars. The shape that is most frequent in Anatolian and Hungarian folk music from among the mentioned ones is the hill. However, while in Anatolian and Hungarian tunes the rate of descending or stagnant lines is considerable, in Kazakh areas - except for the Mongolian Kazakh laments - such forms are rare.

The popular hill-and-vale wave in the first line of Mongolian Kazakh folk tunes also appears in Mangyshlak (South-Western Kazakhstan) but more rarely. Convex, hill-shaped first lines are massively 
represented in the southwestern Kazakh area, while they only occur-rarely, too - among the la-pentatonic tunes of Mongolian Kazakhs which are themselves very rare. Valley-shaped, concave first lines can only be heard among the Mongolian Kazakhs — rather infrequently and rarely in distinct form.

In both areas one can find rising first lines, but this musical solution is not frequent among every Turkic group. An ascending first line is always followed by a descending second line.

Many tunes move on the notes of bi-, tri-, or tetrachords. This may happen without clear schemes but sometimes distinct motifs are repeated. That was seen for example with the popular psalmodic tunes of Mangyshlak whose common features are recitation on the notes of the do-re-mi trichord for a little while and the overall descending tendency of the whole melody, as well as the 5(b3)4 cadences. Such tunes are included in Anatolian and Hungarian folk music in large numbers (see Figure 12).
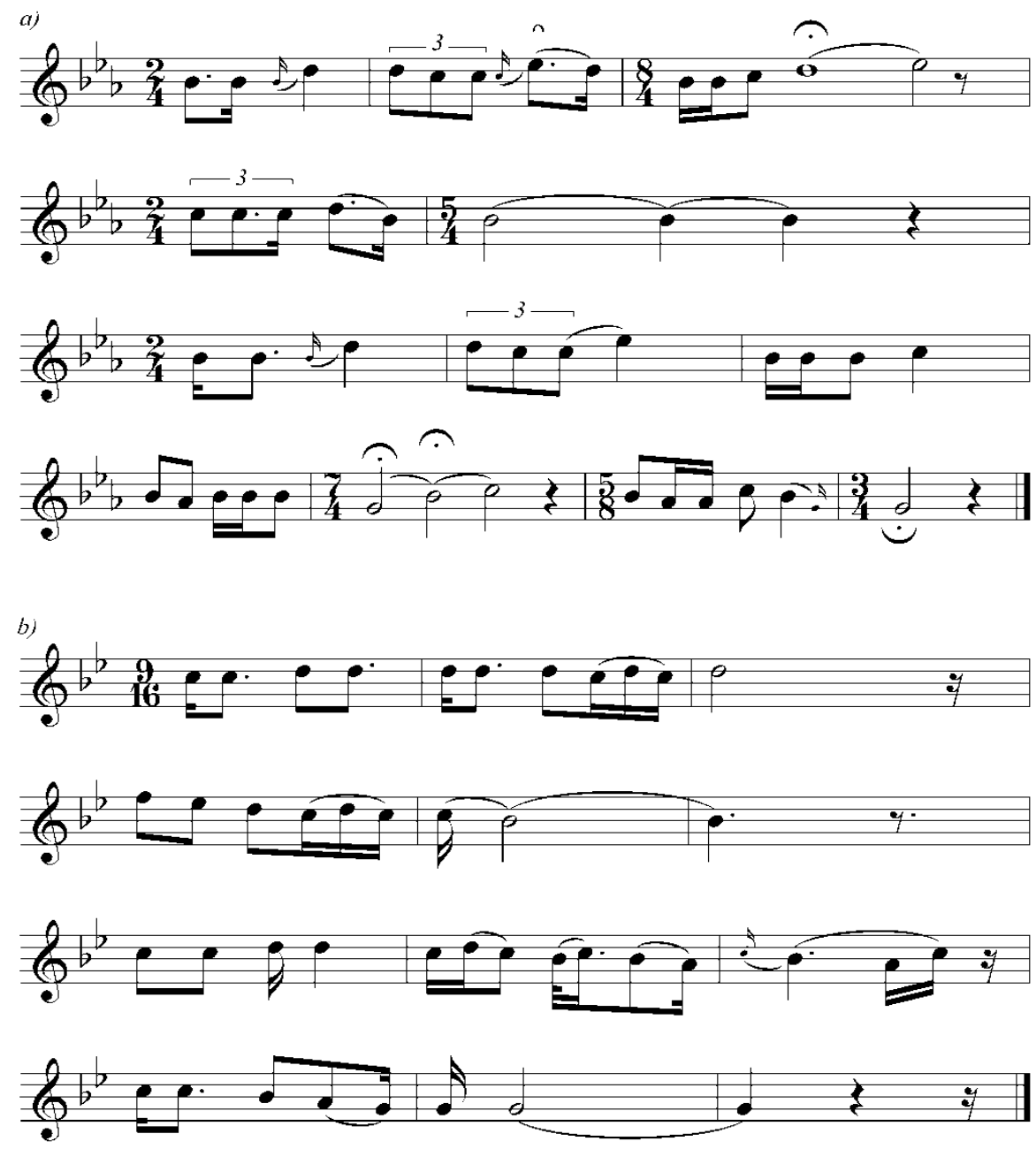


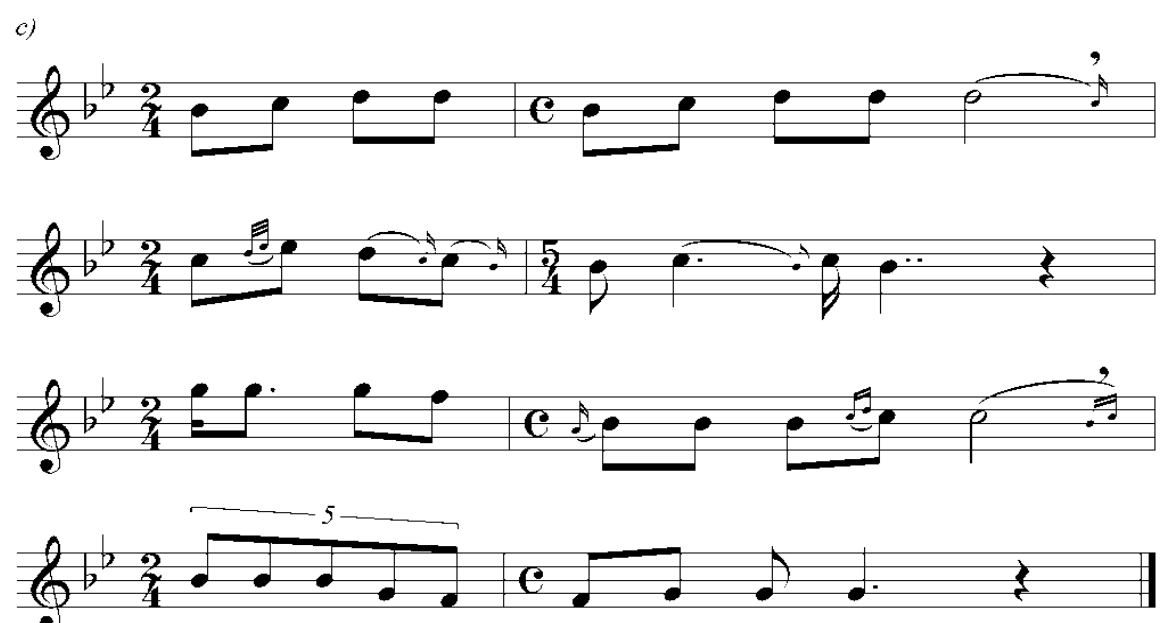

Figure 12. "Psalmodic" melodies a) South-Western Kazakhstan, b) Anatolia (Sipos, 1994, № 127), c) Hungary (Kodály, 1937-1976, № 176).

Several terme tunes of Mangyshlak also belong to the recitative tunes; they are built of lines moving on two or three notes. Some of them remain on the do-re-mi trichord throughout the musical process, but some have a wider compass.

Mongolian Kazakhs also use a kind of psalmodic melody in which the first line moves in a higher register and then comes the recitation on the do-re-mi trichord. Apart from the similar melody contour, the tunes are also tied by the 7(b3)b3 and 7(b3)4 cadences; the difference is that the Mongolian Kazakh tune is do-pentatonic, the Hungarian and Anatolian examples are Aeolian in character.

The first line of many tunes in Bayan-Ölgiy moves up and down in tritony or tetratony. It is not easy to systematize these motions; what binds them together is the up-and-down steps within a fourth or fifth using the notes of pentatony (or the like). Twin bars within a line is not infrequent, and sometimes the whole tune is built of a single bar. It is important to note that such structures are often found among Mongolian Kazakh religious tunes and the tunes of a more recent style in Mangyshlak (see Figure 13).
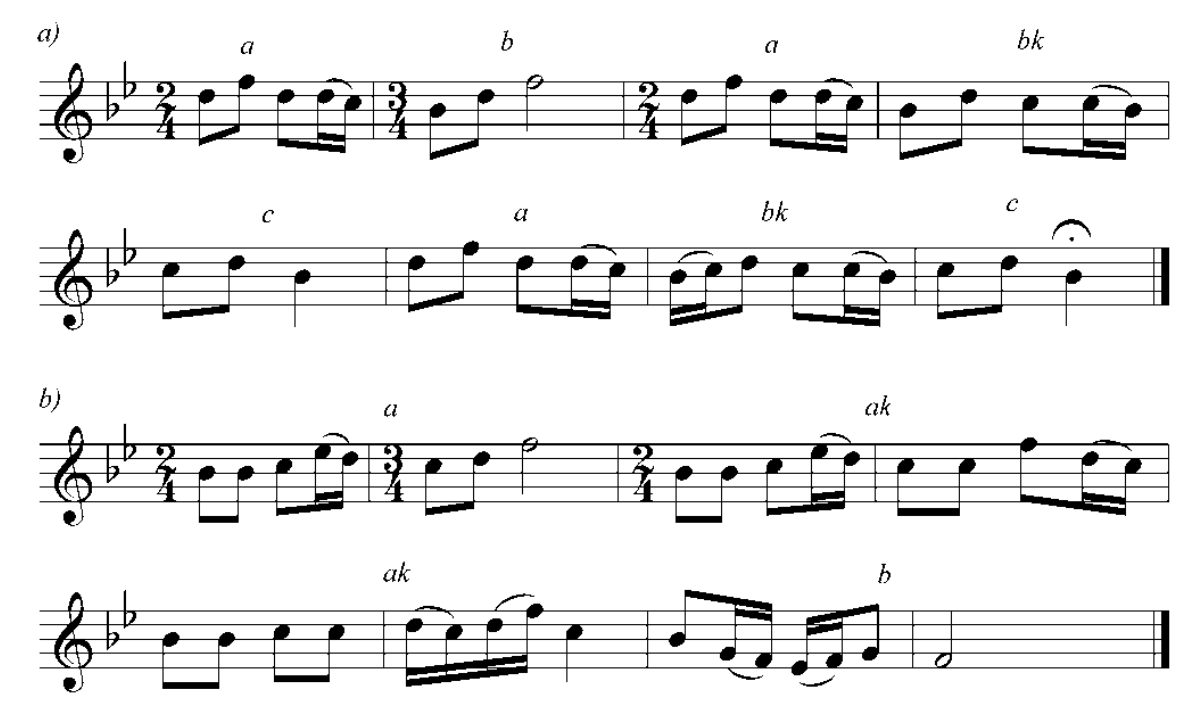

Figure 13. Two melodies from Bayan-Ölgiy moving up and down on a triton or tetraton. 
In view of the enormous territory and the complexity of Kazakh ethnogenesis, it was easy to hypothesize that diverse musical dialects would be found here. Indeed, while the Kazakh tongue is surprisingly homogeneous despite the dialects, in music the divergences are considerable. In Beliaev's (1975) view there are three main dialectal areas. The tunes of South Kazakhstan (the Semirechye, the area of Lake Aral and the Sir-Darya) are characterized by formal simplicity and rhythmic regularity. In the West, beyond the Ural and along the Caspian Sea lyrical solutions are predominant with broad melodies of wide compass, and the presence of termes and recitative forms is also typical. In the central parts of Kazakhstan there is a special wealth of tunes, advanced melodies and complex verse forms.

The do-pentatonic and sol-pentatonic tunes of Mongolian Kazakhs are closer to the pentatonic Mongol-Tatar tune style, while the majority of West Kazakhstan tunes move on scales including the minor third that are so popular in Anatolia (and in Hungarian areas). Data indicate that the music of Kazakhs in China is similar to the music of Mongolian Kazakhs with several variants in diverse areas of today's Kazakhstan. In the two regions I studied the "closer" ethnogenesis was quite apparent, and probably that accounts for the fewer and relatively more homogeneous musical style. This is in sharp contrast with the extraordinary diversity of the Anatolian or Hungarian folk music.

Intricate relations have been discovered about the Kazakh laments. Some threads tie the Mangyshlak lament to its Anatolian counterparts, others connect the Mongolian Kazakh laments to Anatolia. At the same time there is — so far a single-Mangyshlak lament which almost perfectly tallies with the small form of the Turkish and Hungarian lament. It is an important finding that the tunes of psalmodic character are also widely popular in Mangyshlak, too. Many of the other similarities and differences derive from the fact that in Bayan-Ölgiy the do-pentatonic scale is prevalent while in Mangyshlak the diatonic scales with the minor third is. Pentatony goes together with the agility of the tunes and decisively influences their character. This is also an aspect of the folk music of Mongolian Kazakhs that compares it to Chinese and Mongolian music, to the tunes in the Volga-Kama region and in some Hungarian pentatonic styles, while the music of Mangyshlak is closer to the Anatolian Turks, Turkmens and Azeris.

The folk music of the southwestern Kazakh area has not much in common with the broader ranged, mostly pentatonic Chuvash, Tatar, Bashkir, or Siberian Turkic, Uyghur, Mongol and Chinese tunes. In this music modest forms are preponderant, there are often free pre-strophic solutions. There are conspicuously few tempo giusto performed tunes, possibly related to the startling fact that the Kazakhs do not dance, either. Within the pentatonic musical world the Mongolian Kazakh folk music represents a peculiar hue.

\section{Folksongs of the Kyrgyz People}

Kyrgyz folk music, just like the Kazakh, is rather complex. Two large groups emerge from the tunes moving mainly on major-character scales. One is the twin-bar material retraceable to short motifs, which has a still lively richness in the area. The other group resembles the small form of the Hungarian laments. The Kyrgyz tunes can be ranged into five blocks of different sizes and significance.

The twin-bar tunes include the following groups: (a) tunes bouncing on the do-sol bitone, (b) tunes rotating round the middle note of the re-Do-si, mi-Re-do, etc. trichords; (c) the bekbekey tune group and Phrygian tunes with two short lines and $r e$, $d o$ or $m i$ cadence (which closely resemble populous Anatolian, Azeri and Turkmen tune groups moving on the Phrygian scale), (d) tunes starting with a descending or convex, hill-shaped line, with (sol')-mi-re-do-sol descent or do-re-mi-(sol')-mi-re-do-(sol) hill being the most frequent. 
Such twin-bar structures are frequent in the folk music of other Turkic groups, too. Finally, (e) tunes with a jump down at the end of the lines (do-sol, re-la or re-si-la closing patterns).

Tunes progressing along major-character scales can be divided into laments, 2-lined tunes and 4-lined tunes. In the first group we have laments and tunes whose genre and melody outline (e.g. kiz uzatuu 'girls' farewell") subsume them here. The simplest form of major-character Kyrgyz laments and girl's farewell is characterized by a simply performed quasi-major line and its variants. These lines trace a hill of do-re-mi-fa | re-re-mi-fa-mi re $\mid$ do skeleton which may be preceded by a sol-do jump up or followed by a do-sol leap. The two-core form of the Kyrgyz lament has longer descending or hill-shaped lines performed parlando-rubato, cadencing on re and $d o$. This is very similar to the small form of Anatolian, Azeri or Hungarian laments, although the more markedly hill-shaped lines of some Kyrgyz laments lend them a somewhat different character. It is a good indication of the deep embeddedness of this form in Kyrgyz folk music that several Kyrgyz tunes of short lines have the same character. The two-lined tunes of major character have the following groups: (5) main cadence and line 1 undulating on the mi-re-do trichord; (5) main cadence and line 1 tracing a tall hill with sol'/la' peak; (6) main cadence (unlike in most Turkic music, the (6) cadence, even main cadence is not infrequent among the Kyrgyz), and finally, tunes with (7) and (8) main cadences with a higher first melody half. The typical cadential patterns of major-character four-lined tunes are 5(4)x, b3/4(5)5, 5(5)x, 6(6)6 and 5(5)5 as well as 7/8(4/5)x.

Owing to the unstable intonation of the third, too, there is close connection between the minor and major-character laments, so much so that they could have been discussed in one group. What was said of major-character laments applies to the rarer minor-character tunes having fewer forms. The main cadences of two-lined minor tunes are (4) and (5). The first line of four-lined minor character tunes keeps reciting within a narrow tonal strip, or it is convex, sometimes ascending. The typical cadence schemes are 5(2)x and 5/7(b3)x, $4(5) x, 4(4) x, 5(4) x$ and 5/6(5/6)x and 7/8(5/4)x. There is one major-character tune class whose first line is valley-shaped, ascending or undulating by touching on the tonic in mid-line; this feature separates them sharply from the rest of the Kyrgyz tunes. The larger subgroups of these Kyrgyz tunes-those with (4), 4(1)x and (5) cadences - are closely connected to the tunes of the previous class, although there are no laments among them. The cadences of four-lined tunes with an undulating first line are: 4/5(b3)x, 5(4)x and 5/4(5)b3.

Possibly the most important - and certainly the most colourful—element of Ramadan traditions is the singing of Ramadan songs. During the month of fasting the children go from house to house singing and collecting small gifts: in addition to money, candy, various seeds, fruits, etc. Though with smaller intensity than among the Kyrgyz, the Ramadan traditions are also observed by the Uzbeks, Kazakhs, the Ahishka, Uyghur and Anatolian Turks. The Kyrgyz Ramadan tunes deviating widely from their folksongs are introduced in detail in Sipos (2014).

Finally, there are some Kyrgyz tunes whose inner lines are a fourth or fifth higher than the outer lines; this kind of domed structure cannot be found in the archaic styles of Turkic people. The minor-character domed tunes have 1(5)5/4 cadences - that is, their third line also ends high. Line 2 is a variant of line 1 with a higher cadence, or it moves in a higher register. The latter is less frequent and also diverges wide from the typical form of Kyrgyz folksongs, while it more closely resembles, for example, Hungarian new-style songs. The cadence scheme of major-character domed tunes is b3(7)4/5/7, and their melodic progression also contains elements that deviate from the traditional Kyrgyz patterns. 


\section{Folksongs of the Area of the Volga-Kama-Belaya}

If we continue our overview and take a bird's-eye-view of the music of Turkic group in the Volga-Kama region, we find a musical realm of a different character. The folk music of Tatar, Chuvash and Bashkir people is characterized by an almost exclusive use of whole or partial pentatonic scales and often descending melody outlines. The fifth-shift can also be found here, but this marked feature is only present in a $100 \mathrm{~km}$ circle of the Cheremis-Chuvash border zone, among the Cheremis of a Finno-Ugrian tongue only up to the limit of Chuvash Turkic linguistic influence. In the wholly pentatonic music of the Tatars there is no fifth-shifting, but there is fourth-shifting. As seen earlier, pentatonic fourth- or fifth-shifting on a mass scale occurs in Outer and Inner Mongolia, which suggests that maybe it is the vestige of the Mongolian influence during or after the Golden Horde. This hypothesis is further strengthened by the fact that the Bashkir and Tatar uzun küy "long song" also points towards Mongolian folk music.

The folk music of the region is highly complex with narrow and broad-ranged forms of diatony and pentatony, a wide spectrum of melody construction from the repetition of primitive motifs to strictly structured four-lined forms, etc. The distribution of these is, however, most uneven among the different groups.

Let us see what the researcher with first-hand experience of the area-László Vikár (1993, pp. 33-39) - has to say about the music of this region. It is typical to Finno-Ugrian musics to emerge from the repetition of very simple elements, but these primitive elements are repeated and varied in a highly sophisticated manner. Going from north to south, the strophes and melody lines become gradually longer and more regular. The traditional Finno-Ugrian tunes remain within the pentachord frame in quiet, sometimes monotonous, reserved performance. Under Turkic influence, the pentatonic scale and ornamented performance may sometimes occur - or even become predominant in certain areas. Still, the Finno-Ugrian stratum is dominated by a great degree of liberty, a meagre tone set, but powerful variation of the small motifs. Form, line length, syllable number and pitch intonation are all varied. They easily extemporize, do not regard the rigid limitations of strophic performance and a single tone set important. By contrast, the Turkic ethnic groups living here gladly sing, have several attractive strophic tunes whose compass reaches and even exceeds the octave. But obviously the Turkic groups also have simpler melody styles, some Turkic groups-e.g. Azeris, Turkmens and Dobrudja Tatars-having such tunes exclusively.

It is Vikár's (1993, pp. 33-39) observation that progressing from east to west in the Volga-Kama material, one finds increasingly more regular tune structures up to the Cheremis-Chuvash border (fifth-shift limit). Cheremis music is predominated by the so-called small form, Chuvash music by the three-lined structure constituting a transition between the free and more strictly built tune structures. Anyhow, underlying the diversity of tune forms in the region is simplicity. Disregarding now the repetitions, transpositions and smaller or greater rhythmic and melodic changes, we find one or two simple musical cores or a single motif remaining.

Lajos Vargyas (2005, pp. 238-323) also surveyed the folk music of the Volga-Kama region. Below is a summary of his findings about the folk music of Cheremis, Chuvash, Mordvin, Tatar and Bashkir people living in this territory.

The songs of the Finno-Ugrian Cheremis (Mari) people are typically do-pentatonic, sol-pentatonic and la-pentatonic without semitones in about equal proportions, with negligibly few mi-ending or $r e$-ending pentatony. In the north one finds pentatony without semitones, where the small fifth-shifting form $\mathrm{A}^{4} \mathrm{BAB}$ is also typical. Some tunes only move on five, less frequently three or four neighbouring notes of the pentatonic 
scale. The largest group includes fifth-shifting tunes, but they can only be heard in the Chuvash border zone where all the la-pentatonic tunes include the fifth-shift. Cheremis music is characterized by regular forms, the maximal observance of the frames of form-construction. Laments and children's play songs are missing altogether. The tone set is simple, regulated; changeable intonation is not typical, possibly upon Turkic (Tatar) influence.

The Turkic-tongued Chuvash people only use do- and sol-, less frequently la-pentatonic fifth-shifting tunes on areas bordering on Cheremis groups. In the rest of the Chuvash areas the music is surprisingly archaic. The following rates can be gleaned from Lach's Chuvash collection: bi-, tri- and tetratonic tunes $(20 \%)$, do-, sol-pentatonic of the compass of a sixth (22\%), motif-repeating, stichic or twin-bar forms (41\%), two-lined $\mathrm{A}^{\mathrm{v}} \mathrm{A}, \mathrm{A}^{\mathrm{c}} \mathrm{A}, \mathrm{AB}$ forms (40\%), fifth-shift (1\%). Elementary forms thus amount to $60 \%$ in this collection, declining but still not negligible in later collections. There are many $\mathrm{ABC}, \mathrm{AAB}, \mathrm{ABB}, \mathrm{AAA}^{\mathrm{c}} \mathrm{B}$ etc. forms in the repetition of whose internal parts fourth or fifth transposition may occur. The advanced, broadly arched, strictly constructed melody world of the narrow northwestern strip involving the fifth response stands sharply out of this formally and quantitatively simple musical realm. The "small quintal-shift" of the northern Cheremis music is missing there.

The songs of the Mordvins display more or less similar elementary conditions. There are many $l a$-tetratonic, $l a$-pentatonic, sol-pentatonic tunes, several songs are diatonic, but there are few do-pentatonic, tritonic and do-re-mi tunes. Incomplete small tone sets amount to a third of the material (bi-, tri-, tetratonic tunes and a few using do-re-mi trichord). A small tone set enlarged in the direction of diatony (e.g. major tetrachord) also occurs. Pentatonic tunes generally do not go beyond a hexachord. Here too there is a decline in the number of more archaic tunes in the recent publications. As regards form, the music is even more elementary: there are no strophes at all, only motifs and smaller or greater varied lines. It is important to know that the Cheremis are the closest language relations of the Mordvins, but the Mordvins are the most Russified, the Cheremis the most Turkified Finno-Ugrian ethnic groups.

Drastically different is the music of the Votyak minority living in the territory of the Kazan Tatars. It is - if possible - even more elementary and archaic than their neighbours' music, but the overwhelming majority of their tunes move on the do-re-mi trichord sometimes complemented with sol' or la'. Tritonic and tetratonic tunes of such great importance in the music of the other groups are missing, while do-re bitonic tunes do occur. By contrast, the Votyaks who live in their own territory have more advanced pentatonic music. Evidently, the rich music of minority Votyaks is older and more archaic. The Votyak tunes moving on the do-re-mi trichord are related to the Mordvin and Zuryen tunes, while the 4-line pentatonic tunes display Tatar influence. A corroborating fact is that the Votyaks living close to the northern part of Tatarstan and Bashkiria speak Tatar as well.

The music of the Bashkirs essentially differs from Churvash music, being predominated by broad, descending, richly ornamented $d o$-pentatonic tunes. There are no closed forms; in the tunes one can discern either two lines sometimes varied, or the variations of a single line are repeated. In short, they have broadly arched descending do-pentatonic tunes without a drive at distinct form construction.

The Kazan Tatars and Bashkirs are two neighbouring groups speaking practically the same language and their music also has many similar features. Their songs are pentatonic and highly embellished; the Tatar ornaments are milder, subtler, more evenly distributed than those of the Bashkirs. The latter-like the Mongols - have a conspicuous liking for a plethora of voluminous and unbridled virtuosic ornaments with large leaps next to a long-sustained note. 
The Tatars have the most advanced folk music in the region. Nearly all music is pentatonic, but there is some 3-4-tonic more archaic material without closed forms. Unlike in Cheremis, Chuvash and in some Mordvin folk music, pentatony is not exclusively do-based or sol-based, but la-pentatony and re-pentatony is also considerable. There are some fairly archaic forms, too, for example a period or rarely some even less developed forms. The decisive majority of tunes, however, have a sweeping descending outline or a rise to the octave followed by a descent, all in closed forms; there are also tunes whose compass exceeds the octave. The 3-lined or 4-lined tunes usually descend stepwise to the tonic, with some smaller sections being transposed a fourth, fifth, third or sixth. The Tatar and Bashkir songs are conspicuous for their extreme clarity, which is probably a relatively new phenomenon.

The Mishar Tatars sing mainly broadly arched $d o-$, sol-, la-pentatonic tunes. They have a few more primitive forms or two-lined tunes, some tetratonic and major tunes of a hexachord or smaller compass. Fourth-shifting or repetition a third lower may be heard, but the quintal-shift is unknown here.

The Siberian Tatar tunes I had the opportunity to study are advanced 4-line tune of octave or larger compass, sometimes with fourth or other transposition. On the whole, they are similar to the music of the Kazan Tatars.

In line with Lajos Vargyas' overview, it can be contended that the oldest style in the Volga-Kama-Belaya region is represented by the Votyak do-re-mi tunes; complemented with la they constitute a larger group in Mordvin folk music, too, and they also occur sporadically among the Cheremis and Chuvash tunes. The Zuryens (linguistically closest to the Votyaks but living rather far removed from them) repeat four-tone major motifs, with some major and minor pentachords and hexachords also found. The form of the majority of tunes is based on the repetitions of motifs; the melody outline is descending, sometimes with a convex arch at the beginning. All forms of pentatony are missing. In the collections of the cultured Estonians, who live far away from this area, include more advanced major tunes in increasing numbers. They have a "small fifth-shifting" dance tune style of the peculiar motivic structure of $\mathrm{A}^{4-5} \mathrm{BAB}$ as well as semitonal pentatony.

By contrast, along the Cheremis-Chuvash border nearly exclusively fifth-shifting tunes of a broad arch can be found. Among the Kazan (and other) Tatars there is "non-fifth-shifting" pentatony, the melody being laid out in terraced descent within the closed 4-lined form. In the course of the gradual descent fourth correspondence appears at several points, together with its versions at the fifth, sixth and even second; this can be found in Cheremis and Chuvash music, too.

I carried out a thorough examination of fifth-shifting in the music of Turkic people, Hungarians, Mongols and Evenks. The tune groups reveal that closest to each other - in terms of music - is the Cheremis and Chuvash style, with Hungarian music being a distant relative. On the other side is Mongolian folk music with Evenki and North Chinese tunes closely attached to it. The link between the two large blocks is constituted by the la-pentatonic groups with 8(5)4 cadences and-less dominantly-by sol-pentatonic tunes with 7(4)b3 cadences. Several other differences and similarities can be observed.

\section{Conclusion: Grouping of Turkic Folk Music Stocks, Situation of Comparative Research}

Before presenting summary tables let me repeat that repertoires of Turkic folk music are often related to the music of neighboring groups and people they have integrated. In the south there are strong Iranian contacts (Azeri, Anatolian, Turkmen, Uzbek), in the north and east relations to the more broadly arched pentatonic music of the Mongols can be gleaned (Mongolian and eastern-northern Kazakhs, some Siberian Turks, 
Chuvash, Tatar, Bashkir), while in the region of the Caucasus musical fusion with the Cherkes, Kabard, Alan and other Caucasian peoples can be observed (Karachay-Balkar, Nogay). The music of Turkey (also) mirrors the culture of absorbed and Turkified substrata to a great extent, the music of Siberian Turkic groups is basically pentatonic but their music so fundamentally differing from the pentatonic forms of the MongoliaVolga-Kama area requires further thorough comparative investigations. The motivic music of the Yakuts, who migrated to their current area later, also needs further studies as this music differs from the other Turkic repertoires and has forms that are similar to the motivic music of some Finno-Ugrian groups.

Table 1 gives a grouping of Turkic folk music stocks. Group 1 includes the Anatolian Turks with their highly complex non-pentatonic music. Group 2 includes the Azeris who are closely tied to Caucasian and Iranian traditions, and the Turkmens with strong Iranian musical impacts. Group 3 comprises the northern Turkic groups with dominantly pentatonic music: Tatars, Bashkirs, some Altay Turks, Oirats, Tuvans, with close relation to the pentatonic practice of Mongol, Buryat and Chuvash people. In group 4 the Uzbeks with ties to the Iranian Tadjiks can be seen as a separate entity. Group 5 includes the Kazakhs living over a vast territory with their highly compound folk music displaying ties toward south and east. Group 6 includes the Kyrgyz, Khakas and several Altay tribes. Owing to their common nomadic background groups 5 and 6 show several kindred traits.

Table 1

A Grouping of Turkic Folk Music Stocks

\begin{tabular}{|l|}
\hline - 1. Anatolian Turkish \\
\hline - 2. Azeri ( Caucasus) and Türkmen ( Iranian) \\
\hline - 3. Tatar, Bashkir, some Altay Turkic, Oirat, Tuvan ( Mongol, Buryat, Chuvash) \\
\hline$\bullet$ 4. Uzbek ( Tadjik) \\
\hline$\bullet$ 5. Kazakh $(4 \sim 5)$ \\
\hline$\bullet$ 6. Kyrgyz, Khakas and several Altay tribes \\
\hline
\end{tabular}

Table 2 is meant to demonstrate the situation of this comparative folk music research at the moment. We have a relatively clear picture of Oghuz, Kipchak and Chuvash folk music. That is promising because considering their numeric rate, state-creating ability and the size of the area they populate, these ethnic groups comprise the bulk of the Turkic-speaking populace. In the table, I indicate my collections in normal bold type, Vikár-Bereczki's collections in italicized bold type, and the groups whose music has not been included in the comparative research yet are put in parentheses.

Table 2

Linguistic Classification of Turkic Groups

\begin{tabular}{llll}
\hline I. & Common Turkic branch & & \\
\hline 1. & Oghuz & southwestern & Turkish, Azerbaijani, Türkmen, (Gagauz) \\
2. & Kipchak & northwestern & $\begin{array}{l}\text { Kyrgyz, Kazakh, Karachay, Balkar, Bashkir, Kazan Tatar, } \\
\text { (Crimean Tatar, Kharaim, Karakalpak, Nogay, Kumyk) } \\
\text { Uzbek, (yellow Uyghur, modern Uyghur, Salar) }\end{array}$ \\
3. & Turkestani & eastern & (Siberian Tatar, Altai, Shor, Chulim and Abakan Tatar, Khakas, \\
4. & Siberian & northern & Tuvan, Karagas or Tofa) \\
5. & Khalaj & & - \\
6. & Yakut & (Yakut) \\
II. & Bulgar Turkic (Chuvash) & & Chuvas \\
\hline
\end{tabular}

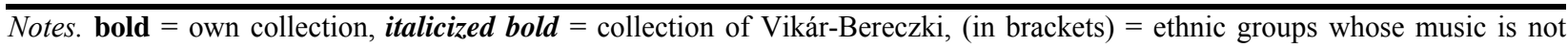
included in the comparative research yet. 
Folk music research, as part of the social sciences, cannot propose finite, petrified theories, and research into the folk music of Turkic ethnicities is far from being completed. Not only are entire ethnic groups missing, but several tasks are still to be done concerning the already studied musical stocks as well.

Collecting work must go on, the relics of traditional tunes and the contemporary repertoire must be surveyed. It is important to create a possibly large, well-documented, accessible (online) digitalized archive; to monographically elaborate the music of certain regions and ethnic groups; to carry out the comparative analysis of the tune stock of Islamic folk religion, among many other tasks. It remains for future research to involve the folk music of Turkestani and Siberian Turkic groups, of smaller Khalaj and Yakut communities, and to continue the Kazakh and Anatolian research. Most of these tasks await local colleagues and international work teams such as the Music of the Turkic-speaking World ICTM team I have founded.

Despite the many tasks ahead of us, I hope that proceeding along the path signposted by our great predecessors, these results in the collection and comparative analysis of the folk music of this enormous area have contributed to its better understanding. I also hope that these investigations will be of help to the practitioners of comparative folk music research and ethnomusicologists adopting the methods of cultural anthropology alike, so that the foundations of an even broader comparative musical research of Eurasia involving even more ethnic groups shall be firmly laid. The review of the folk music of the vast Eurasian territory may also provide data for the confirmation or, conversely, the modification or reconsideration of some results of the prehistory of Hungarian folk music. Finally, a classified, systematized folk music material may help music education, and a large folk music database provides the possibility to illustrate the musical culture of the peoples concerned.

Finally let us review how far the comparative research of the folk music of various Turkic groups has arrived. Table 2 reveals that we have relatively accurate image of the music of Oghuz, Kipchak and Chuvash folk music - thanks primarily to Hungarian researchers (I/1, I/2 and II). This is highly propitious because these numerically and territorially largest groups which also have states of their own constitute the overwhelming majority of the Turkic population.

It will be an important task in the future to include the populous Kazakh, Turkestani and Siberian Turkic as well as the smaller Khalaj and Yakut communities in the research. There are already several books on their music and steps have been taken to launch the analytic and comparative research of these musical stocks. It is therefore not impossible to have a more complete picture of this complex musical world—but the signposted path has to be further trodden.

\section{References}

Bartók, B. (1937). Collecting Folksongs in Anatolia. Hungarian Quarterly, III(2), 337-346.

Bartók, B. (1976). Turkish folk music from Asia Minor. S. Benjamin, (Ed.). (Epilogue by Kurt Reinhard). Princeton, London: Princeton University Press.

Beljaev, V. M. (1975). Central Asian Music. Middletown, Connecticut: Wesleyan University Press.

Beljaev, V. M. (1975). The Music Culture of Turkmenia. In M. Slobin (Ed.), Central Asian Music: Essays in the History of the Music of the Peoples of the U.S.S.R. Middletown, Connecticut: Wesleyan University Press.

Dobszay, L. (1983). A siratóstílus dallamköre zenetörténetünkben és népzenénkben (The Melody Circle of the Lament Style in our Music History and Folk Music). Budapest: Akadémiai Kiadó.

Dobszay, L. (1984). Magyar zenetörténet (Hungarian Music History). Budapest: Gondolat Könyvkiadó.

Dobszay, L. (2010). Az összehasonlító népzenetudomány tündöklése és lehanyatlása (The Rise and Fall of Comparative Ethnomusicology). Magyar Zene, 48(1), 7-19. 
Dobszay, L., \& Szendrei, J. (1992). The Catalogue of the Hungarian Folksong Types Arranged According to Styles I. Budapest: MTA Zenetudományi Intézet.

Járdányi, P., \& Kerényi, G. (Eds). (1961). Magyar népdaltípusok I-III (Hungarian Folksong Types). Budapest: Akadémia Publishing House.

Kodály, Z. (1937-1976). A Magyar Népzene (Hungarian Folkmusic). Budapest: Editio Musica, 1937 (1st ed.), referenses made by the 7 th ed.

Paksa, K. (1982). Kis hangterjedelmü öt- és négyfokú dalaink keleti rokonsága (The Eastern Connecetion of our Small Compass Melodies Moving on Four or Five Tones). Ethnographia, 527-553.

Sipos, J. (1994). Török Népzene I (Turkish Folkmusic I). Mühelytanulmányok a magyar zenetörténethez 14. Budapest: Institute for Musicology of the Hungarian Academy of Sciences.

Sipos, J. (1995). Török Népzene II (Turkish Folkmusic II). Mühelytanulmányok a magyar zenetörténethez 15). Budapest: Institute for Musicology of the Hungarian Academy of Sciences.

Sipos, J. (1997). Bartók Béla törökországi gyüjtése egy nagyobb anyag fényében (Ph.D. dissertation in the library of the Bartók Archives of the Institute for Musicology of the Hungarian Academy of Sciences).

Sipos, J. (2000). In the Wake of Bartók in Anatolia. (Bibliotheca Traditionis Europeae 2). Budapest: European Folklore Institute. [2. kiadása DVD-n: Budapest: Európai Folklór Intézet, 2005.]

Sipos, J. (2001). Kazakh Folksongs from the Two Ends of the Steppe [with CD attachement]. Budapest: Akadémia Publishing House.

Sipos, J. (2004). Azeri Folksongs-At the Fountain-Head of Music [with CD attachement]. Budapest: Akadémia Publishing House.

Sipos, J. (2005)[2006]. Azerbaycan El Havalarl-Musiqinin Illkin Qaynaqlarında (Azeri Folksongs). Bakı: Ebilov, Zeynalov ve ogullar1.

Sipos, J. (2009), Azerbajdzsáni népzene - a zene forrásainál (Azeri Folksongs-At the Fountain-Head of Music [with CD attachement]. Budapest: European Folklore Institute.

Sipos, J. (2014). Kyrgyz Folksongs. Budapest: L’Harmattan.

Szabolcsi, B. (1935). Eastern Relations of Early Hungarian Folk Music. Journal of the Royal Asiatic Society of Great Brotain and Ireland, 3, 483-498.

Szabolcsi, B. (1947). A magyar zenetörténet kézikönyve (Handbook of te Hungarian Music History). Budapest: Magyar Kórus.

Vargyas, L. (2005). Folk Music of the Hungarians. Budapest: Akadémia Publishing House.

Vikár, L. (1982), Régi rétegek a Volga—Káma-i finnugor és török népek zenéjében (Old layers in the music of the Finno-Ugric and Turkic people living in the Volga-Kama area). Zenetudományi Dolgozatok, 323-347.

Vikár, L. (1993). A Volga-kámai finnugorok és törökök dallamai (The melodies of Finno-Ugrian and Turkic groups in the Volga-Kama region). Budapest: Institute for Musicology of the Hungarian Academy of Sciences.

Vikár, L., \& Bereczki, G. (1971). Cheremiss Folksongs. Budapest: Akadémia Publishing House.

Vikár, L., \& Bereczki, G. (1979). Chuvash Folksongs. Budapest: Akadémia Publishing House.

Vikár, L., \& Bereczki, G. (1989). Votyak Folksongs. Budapest: Akadémia Publishing House.

Vikár, L., \& Bereczki, G. (1999). Tatar Folksongs. Budapest: Akadémia Publishing House.

\section{Appendix}

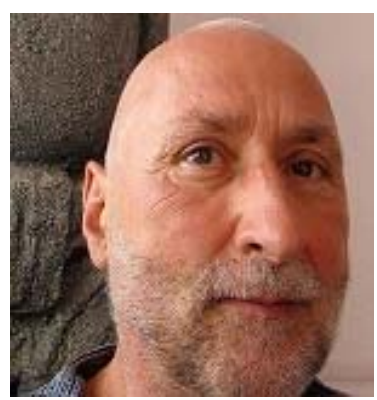

Dr. János SIPOS is a senior research fellow of the Institute for Musicology of the Hungarian Academy of Sciences, Member of the Hungarian Academy of Arts, Hungarian Representative of the International Council for Traditional Music and lecturer of 
the Franz Liszt Music Academy.

In 1978, he had his degree B.Sc. in Mathematics (title of thesis: Computer aided Analysis on Folk Music Rhythms), and in 1999 accomplished his Ph.D. from Linguistics-Ethnomusicology (title of dissertation: Béla Bartók’s Anatolian Research in the Light of a Larger Material). He is a member of numerous scientific societies among others founding member and secretary of the Music of Turkic-speaking People ICTM Study Group.

From 1987 he has been spending some 100 months in areas inhabited by different Turkic people collecting, digiting, transcribing, analyzing and comparing more then 10,000 songs in Anatolia, Thrace, Kazakhstan, Azerbaijan, Kyrgyzstan, Turkmenistan, among Karachays in the Caucasus and Turkey and also among American Indians. Based on his field works he published 17 books. Some of his most important books are as follows:

Török Népzene I-II. (Turkish Folk Music 1-2), Budapest: Institute for Musicology of the HAS, 1994-1995.

In the Wake of Bartók in Anatolia, Budapest: European Folklore Institute, 2000.

Kazakh Folksongs from the Two Ends of the Steppe, Budapest: Academy Publishing House, 2001.

Azeri folksongs - At the Fountain-Head of Music, Budapest: Academy Publishing House, 2004.

The Psalms and the Folk Songs of a Mystic Turkish Order, Budapest: Academy Publishing House, 2009.

Kyrgyz Folksongs, Budapest: 1'Harmattan Publishing House - Institute for Musicology of the HAS, 2014.

Karachay Folksongs, Paris: 1'Harmattan Publishing House - Institute for Musicology of the HAS, 2015. 